\title{
A model study of oceanic mechanisms affecting Equatorial Pacific sea surface temperature during the 1997-98 El Niño
}

Article

Published Version

Vialard, J., Menkes, C., Boulanger, J.-P., Delecluse, P., Guilyardi, E., McPhaden, M. J. and Madec, G. (2001) A model study of oceanic mechanisms affecting Equatorial Pacific sea surface temperature during the 1997-98 El Niño. Journal of Physical Oceanography, 31 (7). pp. 1649-1675. ISSN $0022-$ 3670 doi: https://doi.org/10.1175/15200485(2001)031<1649:AMSOOM>2.0.CO;2 Available at https://centaur.reading.ac.uk/5883/

It is advisable to refer to the publisher's version if you intend to cite from the work. See Guidance on citing.

Published version at: http://journals.ametsoc.org/doi/abs/10.1175/1520-0485(2001)031\%3C1649:AMSOOM \%3E2.0.CO;2

To link to this article DOI: http://dx.doi.org/10.1175/1520-

0485(2001)031<1649:AMSOOM>2.0.CO;2

Publisher: American Meteorological Society

All outputs in CentAUR are protected by Intellectual Property Rights law, including copyright law. Copyright and IPR is retained by the creators or other copyright holders. Terms and conditions for use of this material are defined in the End User Agreement. 


\section{www.reading.ac.uk/centaur}

\section{CentAUR}

Central Archive at the University of Reading

Reading's research outputs online 


\title{
A Model Study of Oceanic Mechanisms Affecting Equatorial Pacific Sea Surface Temperature during the 1997-98 El Niño
}

\author{
Jérôme Vialard,* Christophe Menkes, Jean-Philippe Boulanger, Pascale Delecluse, And \\ ERIC GUILYARDI \\ Laboratoire d'Océanographie Dynamique et de Climatologie, Paris, France \\ Michael J. McPhadeN \\ Pacific Marine Environmental Laboratory, Seattle, Washington \\ GuRVAn MADEC \\ Laboratoire d'Océanographie Dynamique et de Climatologie, Paris, France
}

(Manuscript received 3 January 2000, in final form 10 August 2000)

\begin{abstract}
In this study, the processes affecting sea surface temperature variability over the 1992-98 period, encompassing the very strong 1997-98 El Niño event, are analyzed. A tropical Pacific Ocean general circulation model, forced by a combination of weekly ERS1-2 and TAO wind stresses, and climatological heat and freshwater fluxes, is first validated against observations. The model reproduces the main features of the tropical Pacific mean state, despite a weaker than observed thermal stratification, a $0.1 \mathrm{~m} \mathrm{~s}^{-1}$ too strong (weak) South Equatorial Current (North Equatorial Countercurrent), and a slight underestimate of the Equatorial Undercurrent. Good agreement is found between the model dynamic height and TOPEX/Poseidon sea level variability, with correlation/rms differences of $0.80 / 4.7 \mathrm{~cm}$ on average in the $10^{\circ} \mathrm{N}-10^{\circ} \mathrm{S}$ band. The model sea surface temperature variability is a bit weak, but reproduces the main features of interannual variability during the 1992-98 period. The model compares well with the TAO current variability at the equator, with correlation/rms differences of $0.81 / 0.23 \mathrm{~m}$ $\mathrm{s}^{-1}$ for surface currents. The model therefore reproduces well the observed interannual variability, with wind stress as the only interannually varying forcing.

This good agreement with observations provides confidence in the comprehensive three-dimensional circulation and thermal structure of the model. A close examination of mixed layer heat balance is thus undertaken, contrasting the mean seasonal cycle of the 1993-96 period and the 1997-98 El Niño. In the eastern Pacific, cooling by exchanges with the subsurface (vertical advection, mixing, and entrainment), the atmospheric forcing, and the eddies (mainly the tropical instability waves) are the three main contributors to the heat budget. In the central-western Pacific, the zonal advection by low-frequency currents becomes the main contributor. Westerly wind bursts (in December 1996 and March and June 1997) were found to play a decisive role in the onset of the 1997-98 El Niño. They contributed to the early warming in the eastern Pacific because the downwelling Kelvin waves that they excited diminished subsurface cooling there. But it is mainly through eastward advection of the warm pool that they generated temperature anomalies in the central Pacific. The end of El Niño can be linked to the large-scale easterly anomalies that developed in the western Pacific and spread eastward, from the end of 1997 onward. In the far-western Pacific, because of the shallower than normal thermocline, these easterlies cooled the SST by vertical processes. In the central Pacific, easterlies pushed the warm pool back to the west. In the east, they led to a shallower thermocline, which ultimately allowed subsurface cooling to resume and to quickly cool the surface layer.
\end{abstract}

\section{Introduction}

Because of their huge socioeconomic impact (Glantz 1996), it is important to learn to predict El Niño-Southern

\footnotetext{
* Current affiliation: European Centre for Medium-Range Weather Forecasts, Berkshire, Reading, United Kingdom.

Corresponding author address: Jérôme Vialard, ECMWF, Shinfield Park, Berkshire, Reading RG2 9AX, United Kingdom. E-mail: j.vialard@ecmwf.int
}

Oscillation (ENSO) events. It is thus important to understand the processes at work in the ENSO cycle to make sure that they will be correctly reproduced (or parameterized) in forecast systems. The processes responsible for sea surface temperature (SST) variability, in particular, are crucial to a complete description of the ENSO phenomenon. It is indeed through the development of SST anomalies in the equatorial Pacific Ocean that the atmosphere will produce large-scale wind anomalies and allow the growth of a coupled mode. 
In the past, several empirical studies quantified the oceanic processes contributing to SST variability in the tropical Pacific Ocean, on seasonal and interannual timescales. The early studies of Wyrtki (1981) and Bryden and Brady (1985) were based on box models and a few data. They however suggested that the cooling by equatorial upwelling and warming by atmospheric fluxes were important processes in the eastern Pacific. Using a larger dataset, the studies of Enfield (1986) and Hayes et al. (1991) highlighted that meridional advection induced by the equatorial divergence was also contributing to the eastern Pacific SST budget. Stevenson and Niiler (1983), Hansen and Paul (1984), Bryden and Brady (1989), and Baturin and Niiler (1997) showed that eddies as well play a big role in the cold tongue heat budget. In that region, large fluctuations at 15-45 day timescale are observed north of the equator in the eastern Pacific (Legeckis 1977). These tropical instability waves (TIWs) appear along the front between the warm water of the North Equatorial Counter Current (NECC) and the cold water of the South Equatorial Current (SEC) because of various instability mechanisms (e.g., Philander 1976; McCreary and Yu 1992; Proehl 1996). They induce large equatorward transport of heat, equivalent or stronger than the effect of surface forcing (Stevenson and Niiler 1983; Hansen and Paul 1984; Bryden and Brady 1989; Baturin and Niiler 1997). More recent studies have access to much more data and presumably offer more reliable estimates of the relative importance of the oceanic processes in the seasonal cycle of the cold tongue. Swenson and Hansen (1999) and Wang and McPhaden (1999) agree about the important role of the atmospheric forcing, cooling by vertical processes, and heating by eddies in the eastern Pacific. Swenson and Hansen (1999), who separate the effect of eddies from the meridional advection by low-frequency currents in their estimate, also find an important role of meridional (low frequency) advection by the equatorial divergence. Wang and McPhaden (1999) also examine the budget of the seasonal cycle of SST in the western Pacific. They find that both atmospheric forcing and cooling by zonal advection are important. On interannual timescales, zonal advection becomes the predominant effect in the central-western Pacific (e.g., Picaut et al. 1996; Frankignoul et al. 1996).

These observational studies are thus useful to understand the processes that drive SST variability on the seasonal and interannual timescales. However, they are limited by two factors. First, they cannot evaluate explicitly every term of the heat budget (e.g., vertical mixing, entrainment, and upwelling are difficult to compute directly and must be computed as a residual). Second, these studies are subject to sampling error: they are based on temporal and spatial data coverage that is not always sufficient to resolve all the processes. This is especially true for the heat transported by TIWs: quite high spatial and temporal resolution datasets are needed to resolve satisfactorily these structures (Kennan and
Flament 2000). On the other hand, ocean models give a complete and consistent picture of the circulation and allow a precise evaluation of all terms in the heat budget. They are obviously not subject to "data gaps" and can give a high spatial and temporal resolution of the processes at work. Most modeling studies give a qualitatively consistent picture with that from observations. In the eastern Pacific, vertical processes are the main cause of the SST variability, with the surface forcing acting as a damping (Battisti 1988; Seager 1989; Barnett et al. 1991; Miller et al. 1992, 1993; Huang and Schneider 1995; DeWitt and Schneider 1999). Some studies also suggest a strong role of meridional advection in the east (Harrison et al. 1990; Barnett et al. 1991; Miller et al. 1992, 1993). In the central Pacific, most of these modeling studies agree about the important role of zonal advection, in particular on ENSO timescales (Philander and Seigel 1985; Seager 1989; Harrison et al. 1990; Huang and Schneider 1995; Boulanger and Menkes 2000). But, models also have biases and uncertainties. It could thus be argued that studying the SST balance with a model is a hazardous task since it is sometimes difficult to know excatly to what extent the model processes are coincident with real ones. However, considerable progress has been made in observing the Pacific Ocean at the end of the TOGA decade. For the first time, fully developed in situ and remotely sensed observations such as the TAO array, TOPEX/Poseidon altimeter, or ERS1-2 scatterometers (Grima et al. 1999), SST products (Reynolds and Smith 1994), and drifting buoy climatologies (Reverdin et al. 1994) are available. The most complete coverage is for the 1992-98 period, including the exceptional 1997-98 El Niño event (McPhaden 1999; Wang and Weisberg 2000). High quality datasets are thus available to both force and validate the models.

In this study, a tropical Pacific Ocean general circulation model (OGCM) is forced by a combination of ERSI-2 and TAO wind stresses. It is validated against observations (sea level, SST, TAO in situ temperature and currents, surface current climatology) over the 1992-98 period. The model reproduces the main features of the tropical Pacific mean state and variability. Given this good agreement, the model is then used to investigate the main processes that controlled the SST variability during the 1993-99 period. The 1993-96 period is used to give a qualitative description of the seasonal cycle. The 1997-99 El Niño-La Niña period is then investigated.

This paper is organized as follows: Section 2 is devoted to data and model presentation. In section 3, the model solution is validated against observations. Section 4 is devoted to a description of the 1993-96 period in the model, with an emphasis on analyzing the main processes at work in the SST equation. Section 5 is devoted to a description of the 1997-98 El Niño in the model. Finally, summary, discussion, and conclusions are presented in section 6 . 


\section{Means of study}

\section{a. The modeling approach}

\section{1) Physics OF THE MODEL}

The ocean model used in this study is the updated version of the one described in Vialard and Delecluse (1998a). We will briefly review here its main characteristics. The LODYC model (Madec et al. 1999) is a general circulation model based on primitive equations, including currents, potential temperature, and salinity, solved by a finite-difference scheme on an Arakawa (1972) C grid. The equation of state is computed from the Jacket and McDougall (1995) formulation. The domain covers the tropical Pacific between $30^{\circ} \mathrm{N}$ and $30^{\circ} \mathrm{S}$, $120^{\circ} \mathrm{E}$ and $75^{\circ} \mathrm{W}$. The model has a $1^{\circ}$ zonal resolution and a meridional resolution varying from $0.5^{\circ}$ between $5^{\circ} \mathrm{N}$ and $5^{\circ} \mathrm{S}$ to $2^{\circ}$ at the northern and southern boundaries. The model has 25 levels (with a $10-\mathrm{m}$ resolution down to $150 \mathrm{~m}$ ). The time step is $1.5 \mathrm{~h}$. No-slip boundary conditions and no flux conditions for heat and salt are applied at the bottom and along the coastlines and boundaries. A damping toward Levitus (1982) monthly temperature and annual salinity is used near the southern and northern boundaries. In the $20^{\circ} \mathrm{N}-20^{\circ} \mathrm{S}$ band, the ocean is left free.

In this study, lateral mixing is applied horizontally. The horizontal eddy coefficient is $2000 \mathrm{~m}^{2} \mathrm{~s}^{-1}$, and increases linearly to $7000 \mathrm{~m}^{2} \mathrm{~s}^{-1}$, within $5^{\circ}$ of the western boundary. The turbulent kinetic energy prognostic equation (Blanke and Delecluse 1993) is used to solve vertical mixing. Slight but persistent density inversions often occurred in the surface layer of the Coupled Ocean-Atmosphere Response Experiment region $\left(140^{\circ} \mathrm{E}-180^{\circ}, 10^{\circ} \mathrm{S}-10^{\circ} \mathrm{N}\right)$ of our previous experiments. Such inversions in the surface layer might exist (especially at night) but should be short lived. Our previous parameterization of the vertical physics thus did not generate sufficient mixing to quickly dissipate these unstable situations. A parameterization of vertical convection has thus been added to solve this problem. The "enhanced vertical mixing" parameterization (Lazar et al. 1999) sets the vertical mixing coefficient to $0.5 \mathrm{~m}^{2}$ $\mathrm{s}^{-1}$ at each grid point where the Brunt-Väisälä frequency is negative (while the turbulent kinetic energy scheme seldom generates mixing coefficients stronger than $\left.0.1 \mathrm{~m}^{2} \mathrm{~s}^{-1}\right)$. The result of this added parameterization is to eliminate persistent density inversions (over several months), while allowing short-lived convective events (several hours to several days). This new version of the model behaves very similarly to the one described in Vialard and Delecluse (1998a,b).

\section{2) THE FORCING STRATEGY}

The boundary conditions for the OGCM include surface fluxes of momentum, heat, and salinity. Those are computed from specified wind stress, net heat flux (sep- arated into penetrative solar heat flux and the non-penetrative surface heat losses), and evaporation minus precipitation (no runoff), respectively.

A combination of ERS1-2 scatterometer-derived wind stresses (Bentamy et al. 1996) and TAO-derived stresses (Menkes et al. 1998) are used to force the ocean model (the experiment will hereafter be named the "ERS + TAO run"). The ERS1-2 stresses for the 199398 period were obtained from IFREMER/CERSAT (http://www.ifremer.fr/cersat) and are provided for the globe as weekly averages and on a $1^{\circ} \times 1^{\circ}$ grid. A subset of these data for the Pacific domain was combined with TAO. Briefly, TAO wind stresses are derived from TAO in situ wind, air temperature, sea surface temperature, and relative humidity. A mean 10-m neutral drag coefficient is calculated at each TAO point using Liu et al. (1979) and Smith (1988) algorithms to convert the daily winds into daily stresses. Then these daily averages are averaged into weekly bins centered at the ERS1-2 dates. At each TAO mooring, TAOERS1-2 stress differences are calculated each week and are interpolated onto the ERS1-2 initial grid using objective analysis. These differences are then used to correct the initial ERS1-2 forcing resulting into an ERS + TAO forcing. The ERS + TAO forcing is then interpolated onto the model irregular grid. More details about this procedure can be found in Menkes et al. (1998).

We parameterized the net heat flux at the ocean surface under the form

$$
Q\left(\mathrm{SST}_{m}\right)=Q\left(\overline{\mathrm{SST}}_{o}\right)+\frac{\partial Q}{\partial \mathrm{SST}}\left(\mathrm{SST}_{m}-\overline{\mathrm{SST}}_{o}\right),
$$

where $Q$ is the net heat flux at the ocean-atmosphere interface; $\mathrm{SST}_{m}$ is the model $\mathrm{SST}, \mathrm{SST}_{o}$ the observed SST; overbars designate average seasonal cycle. We take the Reynolds and Smith (1994) SST 1993-96 average seasonal cycle and a 1979-93 daily climatology of the European Centre for Medium-Range Weather Forecasts (ECMWF) reanalysis (Gibson et al. 1997) as estimates of $\overline{\mathrm{SST}_{o}}$ and $Q\left(\overline{\mathrm{SST}_{o}}\right)$, respectively. Barnett et al. (1991) showed that Eq. (1) is a surprisingly good estimate of the interannually varying surface fluxes. In this study, we chose a $-40 \mathrm{~W} \mathrm{~m} \mathrm{~m}^{-2} \mathrm{~K}^{-1}$ for $\partial Q / \partial \mathrm{SST}$, which is certainly a too strong value for the eastern Pacific (Gordon and Corry 1991; Oberhüber 1988; Barnett et al. 1991). However, we kept this choice since lower values resulted in a degraded mean simulated SST.

A constant correction is applied to the freshwater forcing. In contrast with the surface flux feedback term, it has no physical grounds. It is computed as the ad hoc correction to avoid sea surface salinity drift arising from the error in the prescribed freshwater budget. This results in a quite good sea surface salinity mean state, while the correction does not exceed the uncertainties in the freshwater flux. 
3) THE MIXED LAYER HEAT BUDGET IN THE MODEL

One of the main goals in this study is to investigate the surface layer heat budget during the 1997-98 El Niño. The mixed layer budget method described in (Vialard and Delecluse 1998a) has been used. Briefly, this method averages the model temperature tendency terms over the time-varying mixed layer to compute proxies of the physical tendencies used in the bulk mixed layer models (Niiler and Kraus 1977). The model mixed layer is defined diagnostically from the time-varying vertical diffusion coefficients computed by the turbulent kinetic energy scheme. The final equation for the average mixed layer temperature $(\mathcal{T}$, a proxy for $\mathrm{SST})$ reads:

$$
\begin{aligned}
\partial_{t} \mathcal{T}= & -\underbrace{\int_{\mathrm{A}}^{0} u \partial_{x} T d z}_{-h}-\underbrace{\int_{-h}^{0} v \partial_{y} T d z}_{\mathrm{B}}+\underbrace{\int_{-h}^{0} D(T) d z}_{\mathrm{C}} \\
& +\underbrace{\left[\left(\frac{d h}{d t}+w(-h)\right)(\mathcal{T}-T(-h))+\frac{\left(K \partial_{z} T\right)(-h)}{h}\right]}_{\mathrm{D}} \\
& +\frac{Q^{*}+Q_{S}(1-f(-h))}{\rho_{0} C_{P} h} .
\end{aligned}
$$

Here $h$ is the time-varying depth of the model mixed layer, $(u, v, w)$ the components of ocean currents, $D($ ) the model horizontal diffusion operator, $K$ the vertical mixing coeficient for tracers, $Q^{*}$ and $Q_{S}$ the nonsolar and solar components of the total heat flux, $f(-h)$ the fraction of the solar shortwave flux that reaches the depth $h, \rho_{0}$ the seawater reference density, and $C_{P}$ the seawater heat content. The left-hand side of the equation is the total SST tendency. The terms A, B, and C are the averaged contributions over the mixed layer of zonal and meridional advection and horizontal diffusion, respectively. The term D is the effect of exchanges with deeper ocean (comprising entrainment and vertical eddy heat flux at the bottom of the mixed layer: it will be referred to as "subsurface tendency"). The term E is the effect of atmospheric heat flux forcing on the surface layer (it will be referred to as "forcing tendency"). There is a missing term in Eq. (2) (associated with the convergence of vertical speed inside the mixed layer): it is very small and has been grouped to D in the results description. The contribution from each tendency is computed every time step in the model, and monthly averages are stored.

A lot of studies of the SST budget separate the contribution of low-frequency currents and eddies in the advection term. We have done the same in this study. To do this, we rewrite the monthly averages (denoted by overbars) of the terms A, B, and C in Eq. (2) in the following way:

$$
\begin{aligned}
\overline{\mathrm{A}+\mathrm{B}+\mathrm{C}} & =\overline{\int_{-h}^{0}\left(u \partial_{x} T+v \partial_{y} T+\mathrm{D}(T)\right) d z} \\
& =-\overline{\mathbf{u} \partial_{x} \mathcal{T}}-\overline{\mathbf{v} \partial_{y} \mathcal{T}}+\bar{r}+\overline{\int_{-h}^{0} \mathrm{D}(T) d z .}
\end{aligned}
$$

Here, we have simply rewritten the average advection over the layer as the advection computed from vertically averaged quantities over the mixed layer (indicated by bold fonts), plus a residual $r$. We checked that this residual is very small. If we denote deviations from the monthly average by quotes, we can now write:

$$
\begin{aligned}
& \overline{\mathrm{A}+\mathrm{B}+\mathrm{C}}=\overline{\left(\overline{\mathbf{u}}+\mathbf{u}^{\prime}\right) \partial_{x}\left(\overline{\mathcal{T}}+\mathcal{T}^{\prime}\right)}-\overline{\left(\overline{\mathbf{v}}+\mathbf{v}^{\prime}\right) \partial_{y}\left(\overline{\mathcal{T}}+\mathcal{T}^{\prime}\right)}+\bar{r}+\overline{\int_{-h}^{0} D(T) d z} \\
& =\overline{\mathbf{u}} \partial_{x} \overline{\mathcal{T}}-\overline{\mathbf{v}} \partial_{y} \overline{\mathcal{T}}-\left(\overline{\mathbf{u}^{\prime} \partial_{x} \mathcal{T}+\mathbf{v}^{\prime} \partial_{y} \mathcal{T}^{\prime}+r}\right)+\overline{\int_{-h}^{0} D(T) d z} \\
& \underset{\mathrm{A}^{\prime}}{\downarrow_{\mathrm{B}^{\prime}}} \stackrel{\mathrm{C}^{\prime}}{\longmapsto}
\end{aligned}
$$

$\left(\mathrm{A}^{\prime}\right)$ and $\left(\mathrm{B}^{\prime}\right)$ are the zonal and meridional advection by low-frequency (here monthly) currents, and are recomputed from monthly values. Then $\mathrm{C}^{\prime}$ can be computed as $\bar{A}+\mathrm{B}+\mathrm{C}-\left(\mathrm{A}^{\prime}+\mathrm{B}^{\prime}\right)$ : it represents the effect of eddies (contribution to the advection of the timescales shorter than one month). Here $\bar{C}$ has been grouped to the eddy contribution $\mathrm{C}^{\prime}$ because the diffusion in the ocean model is a parameterization of eddies unresolved by the model grid. In the tropical region, most of eddies are explicitly resolved and the diffusion is mainly present for numerical stability; in our results, the term $\bar{C}$ is negligible compared to the other contributions in $\mathrm{C}^{\prime}$.

To summarize: we have separated the total temperature tendency into zonal $\left(\mathrm{A}^{\prime}\right)$ and meridional $\left(\mathrm{B}^{\prime}\right)$ advection 
(a) TP SLA vs model DHA corr

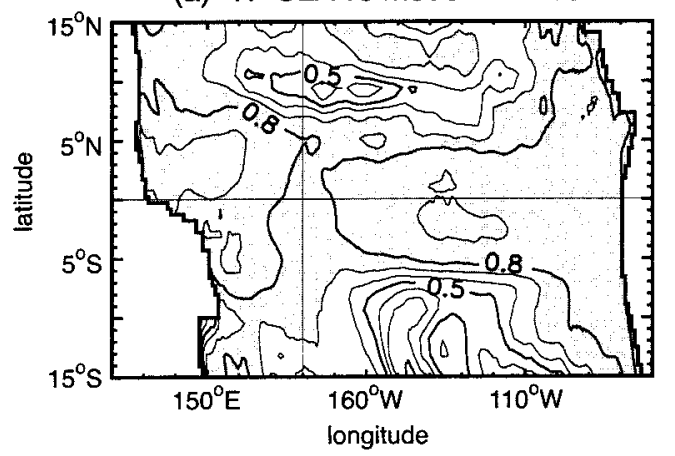

(c) TP SLA std

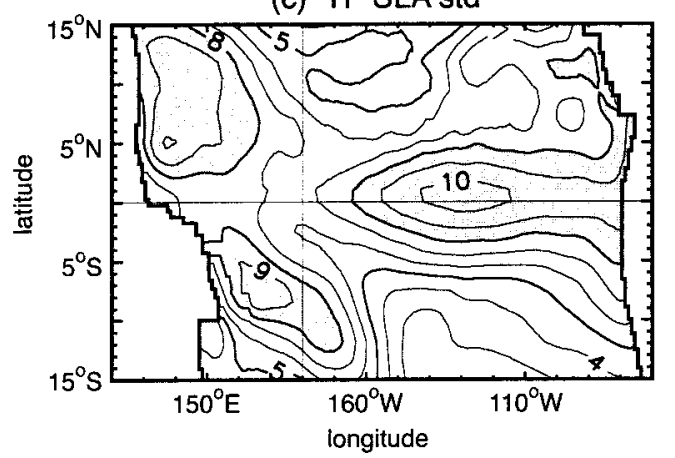

(b) TP SLA vs model DHA rms diff

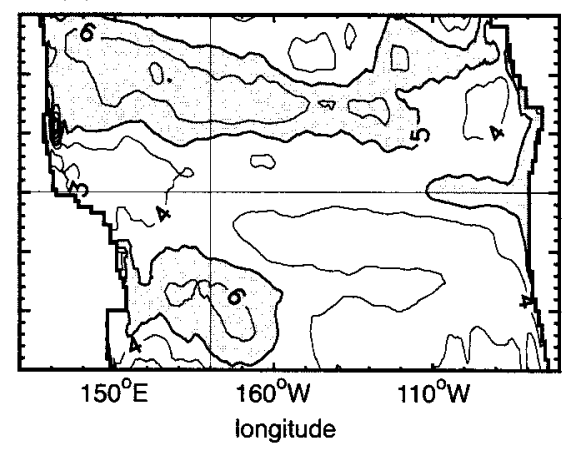

(d) model DHA std

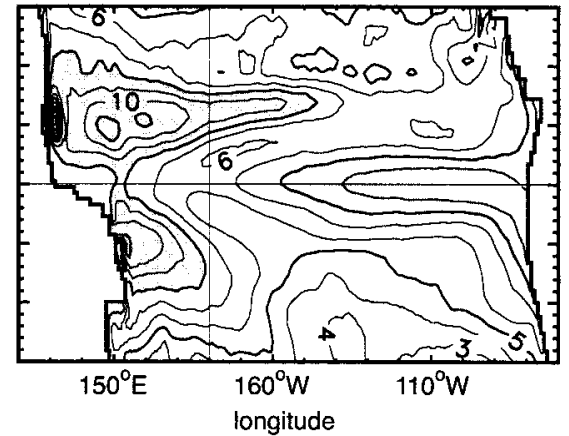

FIG. 1. Comparison between model dynamic height and TOPEX/Poseidon altimetry: (a) correlation (contour 0.1, shading above 0.7), (b) rms difference (contour $1 \mathrm{~cm}$, shading above $5 \mathrm{~cm}$ ), (c) TOPEX/Poseidon standard deviation (contour $1 \mathrm{~cm}$, shading above $8 \mathrm{~cm}$ ), and (d) model standard deviation (contour $1 \mathrm{~cm}$, shading above $8 \mathrm{~cm}$ ).

by low-frequency currents, eddies $\left(\mathrm{C}^{\prime}\right)$, exchanges with the deeper ocean (D), and atmospheric forcing (E). However, several aspects of this separation are questionable. First, it is clear that eddies are associated to strong vertical velocity and mixed layer depth variations. One part of the subsurface tendency contribution (D) could thus be grouped to $\left(\mathrm{C}^{\prime}\right)$. However, this is beyond the scope of this study. We also have defined as "low frequency" all the current variations with periods longer than one month and "eddies" as fluctuations with periods shorter than one month. This is a bit arbitrary since some "large scale" signals can happen at periods very near to one month (e.g., intraseasonal Kelvin waves). Similarly, there is not a clear cutoff at 30 days in the spectrum of TIWs (the main contributor to eddies in this study). However, in section 4, we will show that this mathematical decomposition indeed captures most of the variability associated with eddy-induced advection in our model. Furthermore, our estimate of the effect of eddies is in good agreement with several observational studies (section 6b), which gives more confidence in our approach.

\section{b. Validation dataset}

\section{1) TOPEX/PosEIDON SEA LEVEL ANOMALIES}

The TOPEX/Poseidon (hereafter T/P) sea level anomalies provided by the University of Texas (http:// ftp.csr.utexas.edu/sst/gsdata.html) are used in this study. These data are provided on a $1^{\circ} \times 1^{\circ} \times 10$ day regular grid. The typical accuracy of these data is $2 \mathrm{~cm}$. Depending on the comparisons that are made in the following, we compute anomalies either with respect to the long-term 1993-98 mean or, when stated, with respect to the 1993-96 seasonal cycle. The choice of the short 1993-96 time period for computing a seasonal cycle can be justified by the weak interannual anomalies during that period of time (Boulanger and Menkes 1999).

\section{2) Reynolds And Smith (1994) SST}

A damping toward a climatological seasonal cycle, computed from Reynolds and Smith (1994) 1993-96 data, enters the model formulation [as seen in section $2 \mathrm{a}(1)]$. The total model SST field thus cannot be fairly validated against this product. It must however be underlined that no relaxation toward observed interannual SST anomalies enters the model-forcing formulation. Modeled interannual SST can thus be validated against observed interannual SST (all anomalies being computed with respect to the 1993-96 average seasonal cycle). Sea surface temperature data from the Reynolds and Smith (1994) weekly data are used. These data are processed from the original $1^{\circ} \times 1^{\circ} \times 7$ day bins to 
(a) Model DHA

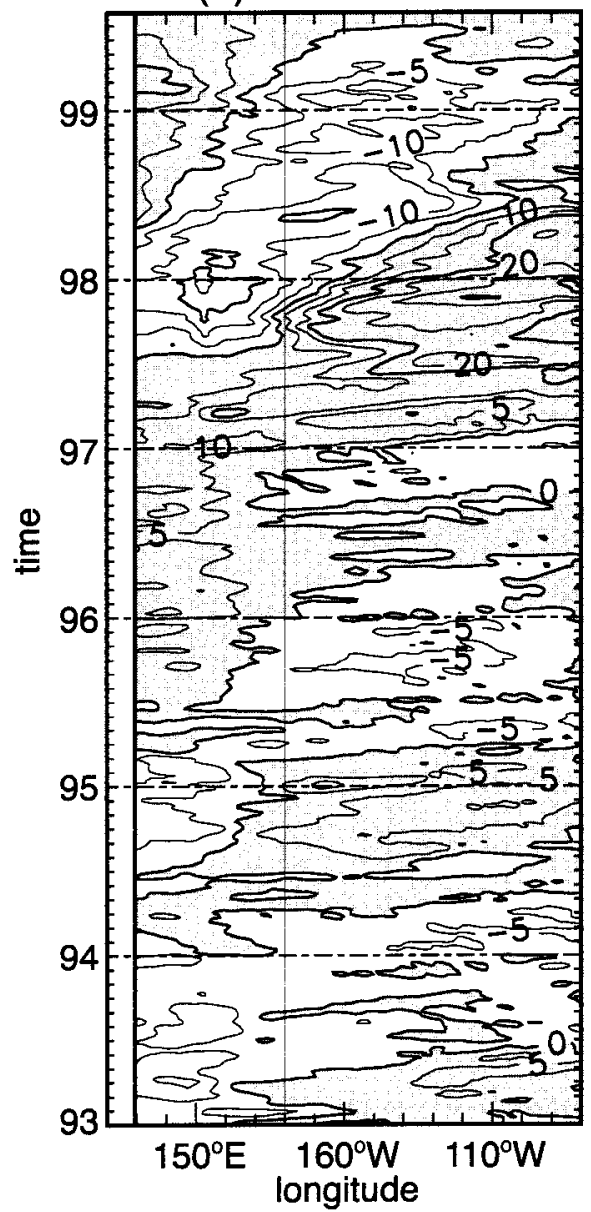

(b) Topex SLA

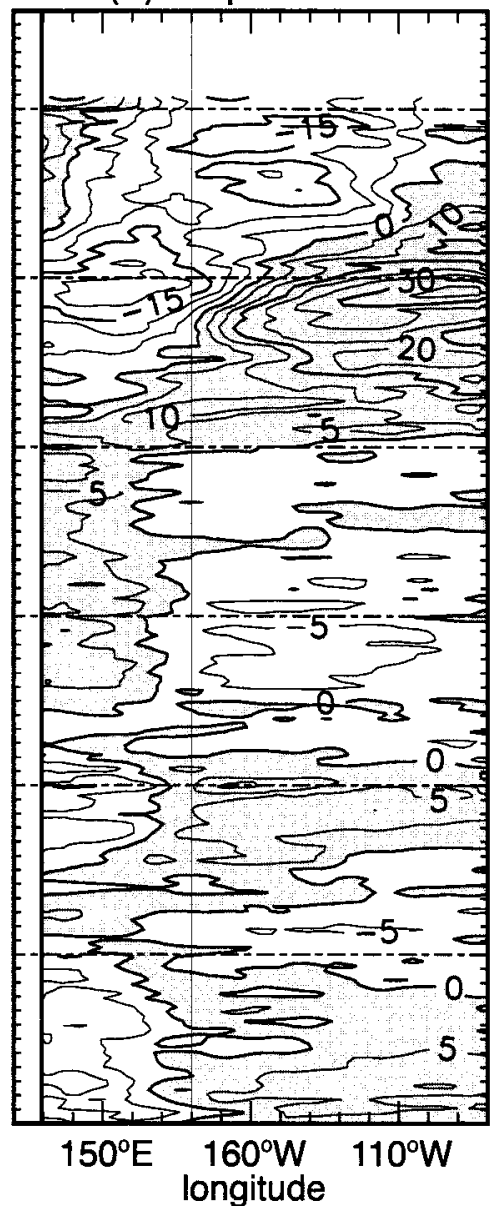

FIG. 2. Time-longitude diagram of (a) model dynamic height and (b) TOPEX/Poseidon altimetry along the equator. Anomalies are computed with respect to the 1993-96 period mean. Contour $5 \mathrm{~cm}$, shading above $0 \mathrm{~cm}$.

the model grid. Errors in this SST product are typically less than $0.5 \mathrm{~K}$.

\section{3) TAO DATA}

In situ temperature and current data from the Tropical Atmosphere Ocean array (Hayes et al. 1991; McPhaden et al. 1998) are extensively used in this study. Vertical profiles of zonal current from equatorial TAO moorings at $147^{\circ} \mathrm{E}, 156^{\circ} \mathrm{E}, 165^{\circ} \mathrm{E}, 170^{\circ} \mathrm{W}, 140^{\circ} \mathrm{W}$, and $110^{\circ} \mathrm{W}$ are used to estimate the accuracy of the model zonal current. At certain times and depths, there are gaps in the data. The gaps in the time series are filled by combining closest levels and times whenever possible, using McCarty and McPhaden (1993) regression methods (Boulanger 2000). Similar methods are used to fill gaps in the TAO temperature profiles. Filled data gaps do not exceed $10 \%$ of the total data at most locations. Daily current and temperature data are then averaged into 5day bins for comparison with model outputs. Errors in
TAO currents and temperature are typically a few centimeters $\mathrm{s}^{-1}$ and $0.1 \mathrm{~K}$ or less, respectively.

\section{4) REVERDIN ET AL. (1994) SURFACE CURRENTS}

Reverdin et al. (1994) have produced a climatology for surface currents in the tropical Pacific. It has been constructed from a combination of surface drifters and TAO equatorial surface currents at $15 \mathrm{~m}$ for the January 1987-April 1992 time period and mapped onto a $5^{\circ} \times$ $1^{\circ}$ regular grid using an objective analysis. Sampling errors are of the order of $7 \mathrm{~cm} \mathrm{~s}^{-1}$ in most of the equatorial Pacific. The model outputs at $15-\mathrm{m}$ depth have been mapped on a similar horizontal grid, and a mean has been calculated over the 1993-96 period. Although the observed and modeled climatologies are not calculated over the same time period, this allows a qualitative validation of the model currents. 
(a) Model SST anomaly

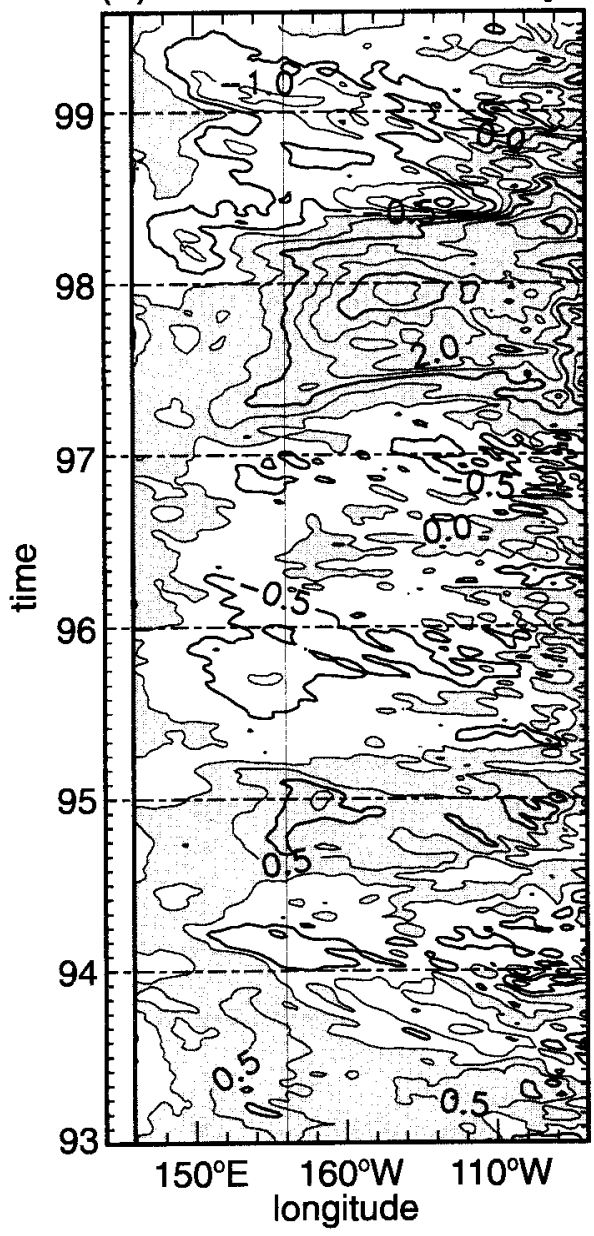

(b) Obs. SST anomaly

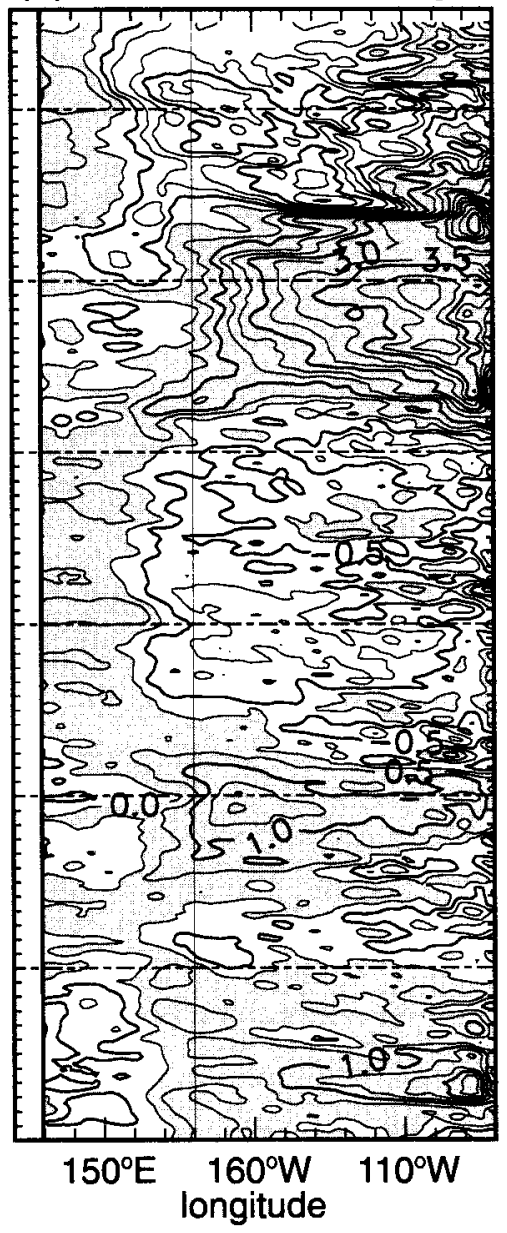

FIG. 3. Time-longitude diagram of (a) model and (b) Reynolds and Smith (1994) SST anomalies along the equator. Anomalies are computed with respect to the 1993-96 period mean. Contour $0.5 \mathrm{~K}$, shading above 0 .

\section{Validation of the model}

\section{a. Dynamic height}

\section{1) BASIN-SCALE VARIABILITY}

Dynamic height anomalies (DHA) are good proxies for sea level anomalies (SLA) in the Tropics. The 10day, 500-dbar dynamic height anomalies computed using the ERS + TAO run in situ densities, including the effect of salinity, (hereafter ERS + TAO DHA) are evaluated against the 10-day T/P sea level anomalies (SLA). Results are presented in Fig. 1.

In agreement with the results of Grima et al. (1999) using ERS1-2 stress forcing, Fig. 1a shows that the overall correlation between ERS + TAO DHA and T/ P SLA is quite good in the $10^{\circ} \mathrm{S}-10^{\circ} \mathrm{N}$ band $(0.80$ on the average, the rms difference being $4.7 \mathrm{~cm}$ ). In particular, this experiment reproduces fairly well the observed variability between the equator and $5^{\circ} \mathrm{N}$ in the eastern Pacific, where there is a strong intraseasonal observed variability due to tropical instability waves (e.g., Baturin and Niiler 1997). Nevertheless, there is a region centered on the date line, with low variability on interannual timescales (Boulanger and Menkes 1999), where correlation is lower than elsewhere in the equatorial band. All models, from linear to complex ones show this low correlation pattern (e.g., Boulanger 2000). This systematically low correlation could be due to the fact that low amplitude variability in this region results in a low signal to noise ratio.

Outside the $10^{\circ} \mathrm{S}-10^{\circ} \mathrm{N}$ band, correlation decreases dramatically. Around $10^{\circ} \mathrm{N}$, rms differences also experience a sharp increase, indicating a large disagreement between the ERS + TAO run and the observations (Fig. 1b). This weak correlation persists when computing the same statistics with bimonthly averages. This poor performance thus does not come from unpredictable high-frequency variations, and reasons for it are still unclear. A decrease of correlation should however be expected toward higher latitudes where synoptic var- 

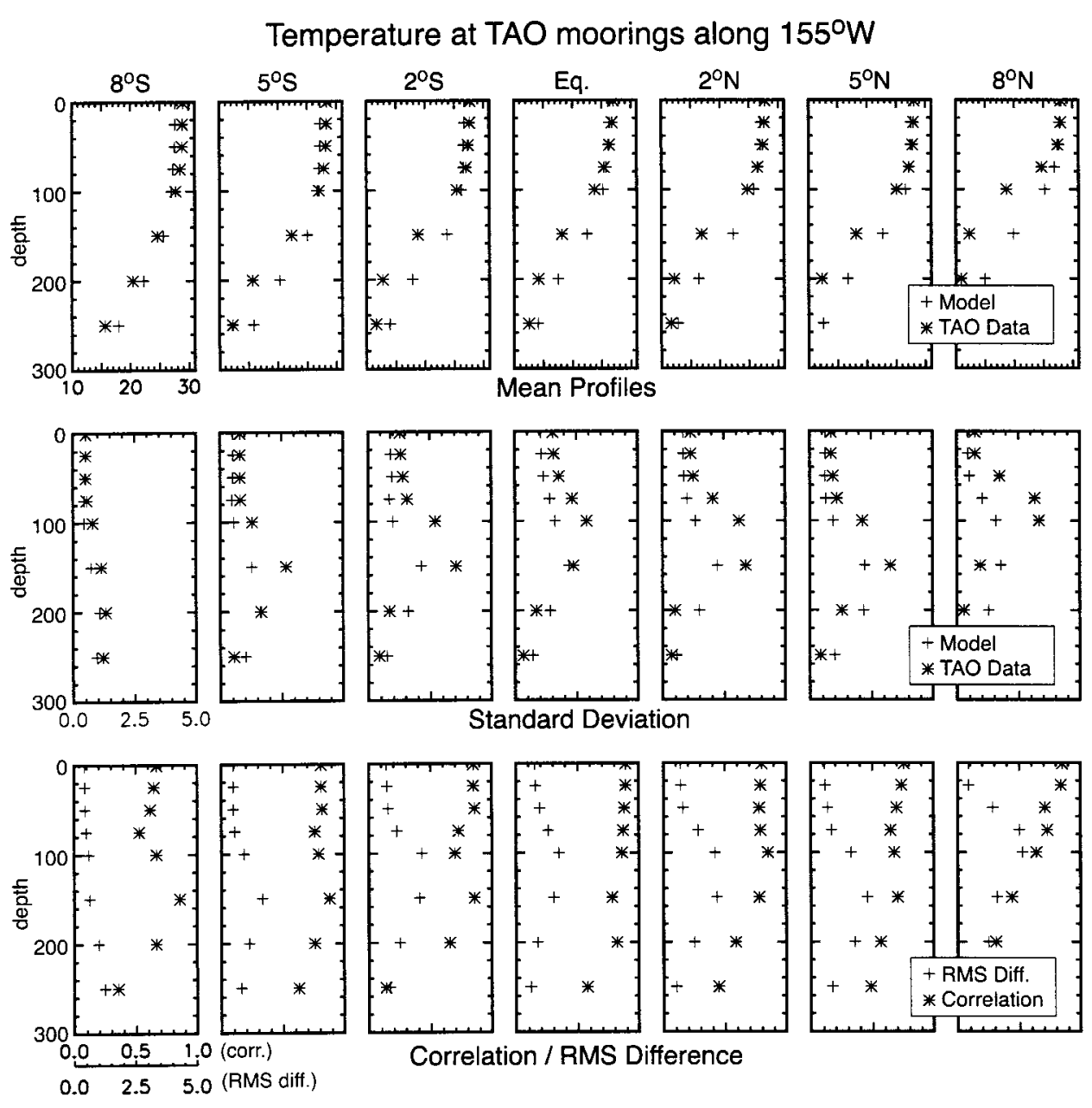

FIG. 4a. Comparison between model and TAO in situ temperatures along $155^{\circ} \mathrm{W}$ at $8^{\circ} \mathrm{N}, 5^{\circ} \mathrm{N}, 2^{\circ} \mathrm{N}$, the equator, $2^{\circ} \mathrm{S}, 5^{\circ} \mathrm{S}$, and $5^{\circ} \mathrm{S}$.

iability, unresolved by the model grid, becomes more important. Furthermore, at these latitudes, the sea level responds to the curl of the wind stress, computation of which involves spatial derivatives of the wind stress, and thus amplifies small-scale noise in the wind field (McPhaden et al. 1988). On the other hand, near the equator the sea level tends to respond to the zonal integral of the zonal wind stress, which tends to smooth out some of the random errors on the winds.

Maps of standard deviations (std) of ERS + TAO DHA and T/P SLA are presented in Figs. 1c and 1d. Both std patterns show similar spatial structure over the basin. These patterns are strongly marked by the 199798 El Niño. In particular, one recognizes the eastern Pacific narrow maximum centered on the equator that is characteristic of remotely forced Kelvin waves and the off-equatorial lobes of equatorial Rossby waves (Boulanger and Menkes 1999). Besides these nicely reproduced large-scale patterns, and a level of variability close to the observed one, the model exhibits several flaws. First, it seems to produce too strong Rossby waves in the western Pacific compared to T/P. Also, some details of observed variability (e.g., the maximum std pattern observed in the $\mathrm{T} / \mathrm{P}$ data near $130^{\circ} \mathrm{W}$ ) are not well reproduced in the model. Again, it is not so clear why the model and the observed std display these discrepancies.

\section{2) VARIABILITy ALONG THE EQUATOR}

Figure 2 shows a time-longitude diagram of modeled DHA and T/P altimetry along the equator over the 1993-99 period. As expected from earlier statistics, there is a good agreement in phase between the model and T/P (with correlation above 0.8 along the equator; see Fig. 1a). In particular, individual Kelvin wave propagation is very clear in the model at the same time as in the observations (e.g., the wave front starting from the western Pacific in early 1997). The model DHA at $4^{\circ} \mathrm{N}$ (figure not shown) displays similar characteristic to the observed SLA, including Rossby wave propagation discussed in (Boulanger and Menkes 1999). It can how- 

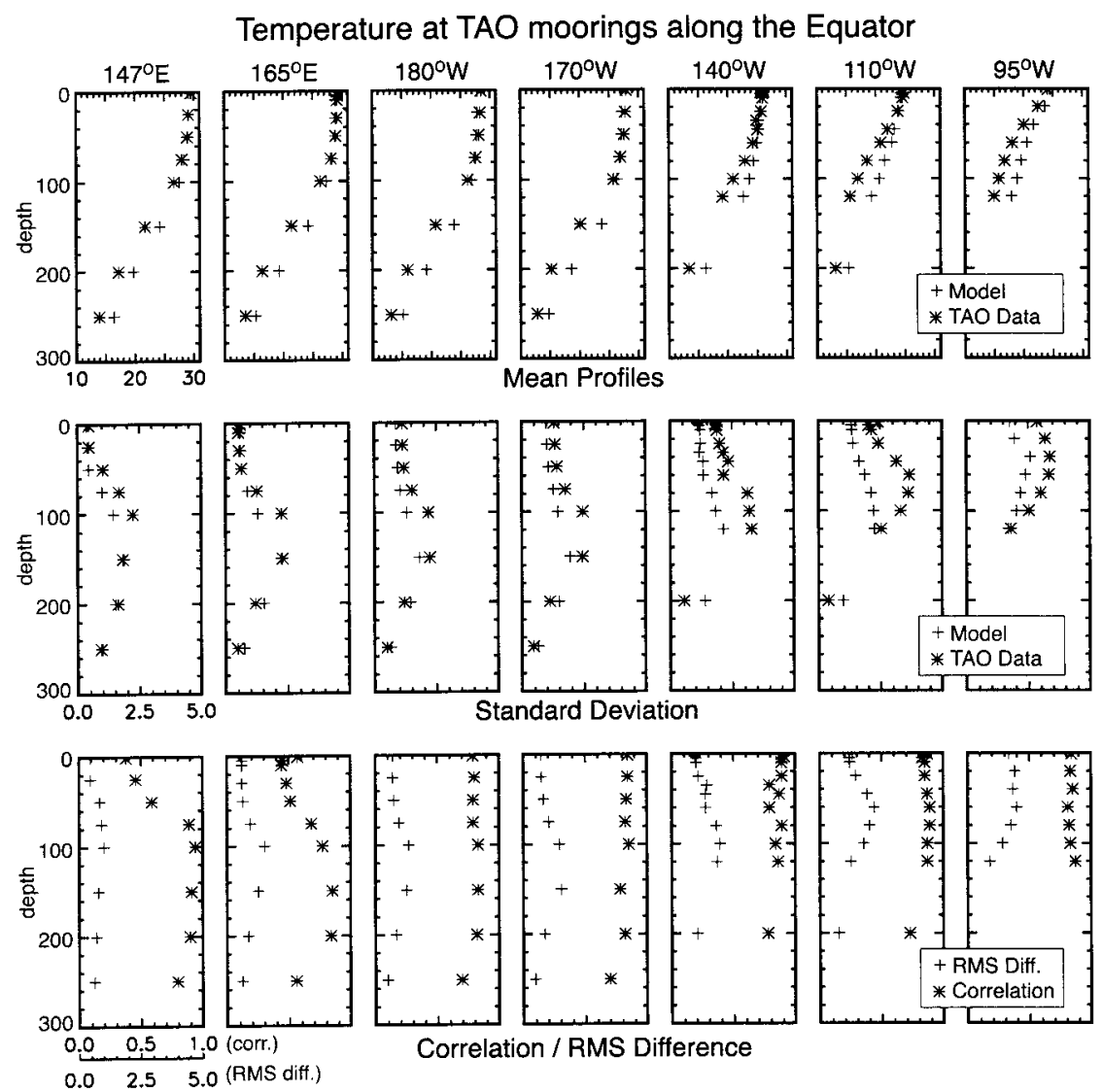

FIG. 4b. Comparison between model and TAO in situ temperatures along the equator at $147^{\circ} \mathrm{E}$, $165^{\circ} \mathrm{E}, 180^{\circ}, 170^{\circ} \mathrm{W}, 140^{\circ} \mathrm{W}, 110^{\circ} \mathrm{W}$, and $95^{\circ} \mathrm{W}$.

ever be noted that waves propagate slightly slower in the model than in the observations. In section $3 \mathrm{~b}$, it will be shown that the temperature vertical stratification is underestimated in the model. In an idealized two-layer linear model, the wave speed propagation is proportional to the density difference between the two layers. The underestimated stratification of the model might thus explain the slightly too slow wave propagation.

Besides the agreement for wave propagation at intraseasonal scale, the model reproduces as well the lowfrequency variability in the observations. During the 1993-95 weak El Niños, the heat content of the warm pool is slightly depleted (with dynamic height lower than normal). From mid-1995 and during all of 1996, there is a buildup of heat content in the warm pool, presumably due to downwelling Rossby waves forced in the central Pacific by stronger than usual easterlies (McPhaden 1999; Boulanger and Menkes 1999). Then, associated to the 1997-98 El Niño, the model reproduces the slow eastward propagation of heat content anomalies discussed by McPhaden and Yu (1999) and largely explained in terms of forced Rossby and Kelvin waves.

At this point, we have demonstrated that the wind product we use gives adequate simulations of SLA in the equatorial Pacific. Yet, as shown by the success of linear modeling, SLA is a relatively easy parameter to simulate and it only gives a vertically integrated measure of oceanic variability. Therefore, it is useful to extend our analysis to the vertical structure of variables such as currents and temperature.

\section{b. Thermal structure}

\section{1) Surface TEMPERATURE INTERANNUAL ANOMALIES}

Figure 3 shows a time-longitude evolution of the modeled and observed SST interannual anomalies (with respect to the 1993-96 period). Despite the absence of relaxation to an interannual SST product, the model reproduces the main qualitative features of interannual variability during the 1993-99 period. Warm and cold periods are reproduced, but the modeled SST variations are systematically lower than observed (e.g., the SST anomaly is only $3 \mathrm{~K}$ at the 1997-98 El Niño peak in the model, compared to $4.5 \mathrm{~K}$ in observations). This might be expected, as the formulation of the interannual flux [Eq. (1)] contains a relaxation to the climatology with a spatially constant $\partial Q / \partial \mathrm{SST}$ value of $-40 \mathrm{~W} \mathrm{~m}^{-2}$ 
$\mathrm{K}^{-1}$. First the interannual flux dependence on SST is more complex than a simple linear relaxation (Seager 1989). Also, the $-40 \mathrm{~W} \mathrm{~m}^{-2} \mathrm{~K}^{-1}$ value is certainly too strong (Gordon and Corry 1991), especially in the eastern Pacific where it should be around $-10 \mathrm{~W} \mathrm{~m}^{-2} \mathrm{~K}^{-1}$ (Barnett et al. 1991). Simulation with a spatially constant $-15 \mathrm{~W} \mathrm{~m}^{-2} \mathrm{~K}^{-1}$ gave a much better agreement with observed interannual SST anomalies, but resulted in a degraded mean state. We thus decided to present results for the $-40 \mathrm{~W} \mathrm{~m}^{-2} \mathrm{~K}^{-1}$ value.

Another feature that is not very well represented by the model is the fact that the maximum SST anomaly is located in the central Pacific rather than near the American coast. This feature might once again be related to the simple parameterization of the surface fluxes we are using, or to the horizontal diffusion used in the tracer equations (Maes et al. 1997).

\section{2) Vertical structure}

Times series of the 5-day temperature structure of the ERS + TAO run were extracted at the TAO mooring locations every time that data were available during the 1993-98 period. The model level closest to the observation point was selected (the separation is never larger than $10 \mathrm{~m}$ ). TAO and model data available at the same times were used to form averages, standard deviations, correlations and rms differences over the 1993-98 period. Figure $4 \mathrm{a}$ shows this comparison along $155^{\circ} \mathrm{W}$ (which captures the essential features of the comparison at other longitudes). Figure $4 \mathrm{~b}$ shows a similar comparison along the equator. These sections are sufficient to illustrate the model performance within the domain of interest.

Figure 4a shows a good agreement between the ERS + TAO run and observations, with close mean states and variability (correlation often in the $0.7-0.9$ range). Some discrepancies can be noticed. The modeled thermocline is too diffuse (due in particular to a too warm deep ocean). Thermal variability is thus underestimated there (see the middle panels where modeled standard deviation is systematically underestimated). It is worth pointing out that the model displays similar flaws when forced by other wind products (e.g., Menkes et al. 1998). This points to internal model deficiencies, possibly linked to the mixing formulation, rather than forcing problems.

These two biases (diffuse thermocline and weak variability) are present in all of the $10^{\circ} \mathrm{N}-10^{\circ} \mathrm{S}$ band. The equatorial section comparison (Fig. 4b) indicates slightly growing discrepancies in the mean state when going from west to east (evident in both mean and rms difference profiles). It can also be noted that the correlation of modeled and observed temperature is low in the surface layer of the western Pacific $\left(147^{\circ} \mathrm{E}\right.$ and $\left.165^{\circ} \mathrm{E}\right)$. It must be pointed out that the variability is very weak there, thus leading to low signal to noise ratio. Furthermore, in this region, the atmospheric heat fluxes are presumably more important in driving SST variability than in the east: the poor performance of the model may be explained by the simple surface flux formulation that we use.

Except in the western Pacific surface layer, correlation between the model and observations is quite high and remains homogeneous in the vertical. This is true even in regions where rms differences between the model and observations are relatively high. The model - observation discrepancy in these areas thus stems from systematic bias and underestimated variability, but the phase of the model variations is good. In summary, despite some disagreements, the ERS + TAO temperature vertical structure agrees well with the observations both in terms of the mean state and variability.

\section{c. Currents}

\section{1) SURFACE CURRENTS}

In this section, we compare Reverdin et al. (1994) mean current climatology with the ERS + TAO run surface currents. It must be kept in mind that this climatology was computed over the 1987-92 period. This is a different base period to the one we use in this study (1993-96). Therefore a quantitative assessment of the model, as in the next section, will not be possible. However, qualitative comparisons between the two climatologies (Fig. 5) reveal some interesting features. First, there is good general agreement between the observed and modeled surface currents. The SEC flows westward, in response to the easterly trade wind forcing. There is a minimum of westward current at the equator, in the east that separates the SEC into two branches, north and south of the equator. This minimum is certainly associated with vertical advection or upward mixing of eastward momentum of the Equtorial Undercurrent (Bryden and Brady 1985; McPhaden and Taft 1988, Maes et al. 1997). The NECC is flowing eastward along $7^{\circ} \mathrm{N}$ in both the model and the observations. Other current systems, off the equator, are well simulated by the model.

Despite this qualitative agreement, the model displays some biases. First, the SEC seems too strong in the simulation (by about $0.1 \mathrm{~m} \mathrm{~s}^{-1}$ ) and penetrates too far west (the eastward bias reaches $0.2 \mathrm{~m} \mathrm{~s}^{-1}$ around the date line). The separation of the SEC in two branches in the east is not as marked as in the observations. Second, the NECC is underestimated by about $0.1 \mathrm{~m} \mathrm{~s}^{-1}$. Some of this problem may be due to inadequacy of the forcing to accurately describe the wind stress curl and/or to some mixing problems in the modeled ocean. Horizontal diffusion can also be partly incriminated. The use of isopycnal diffusion improves off-equatorial current strengths by steepening the temperature gradients resulting in stronger geostrophic currents (Lengaigne et al. 2000, unpublished manuscript).

\section{2) Vertical structure along the equator}

Time series of 5-day TAO and modeled zonal current were formed using the same method as in section $3 b(2)$. 
(a) Model 1993-96 average surface currents
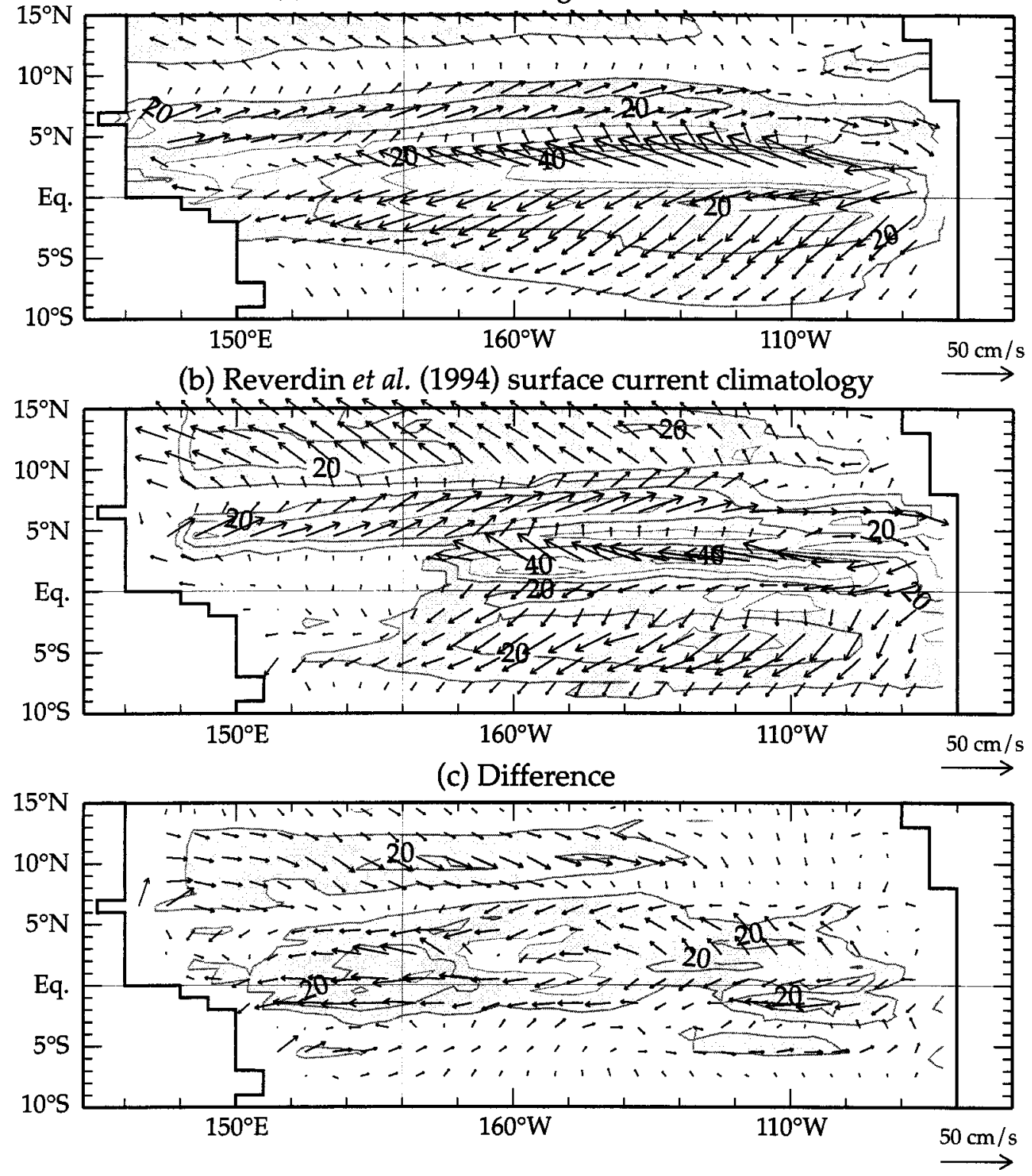

FIG. 5. Comparison between (a) the model 15-m currents, averaged over 1993-98, and (b) Reverdin et al. (1994) climatology, representative of the Jan 1987-Apr 1992 period (contour $20 \mathrm{~cm} \mathrm{~s}^{-1}$ ) and (c) difference (contour 10 $\mathrm{cm} \mathrm{s}^{-1}$ ).

The resulting comparisons are shown along the equator at $147^{\circ} \mathrm{E}, 156^{\circ} \mathrm{E}, 165^{\circ} \mathrm{E}, 170^{\circ} \mathrm{W}, 140^{\circ} \mathrm{W}, 110^{\circ} \mathrm{W}$ in Fig. 6.

The mean vertical profiles of the ERS + TAO zonal current are globally in very good agreement with observations. In the central and eastern Pacific, the model reproduces well the westward flowing SEC at the surface, and the eastward flowing Equatorial Undercurrent (EU) beneath. In the western Pacific, even the subtle layered structure of the flow, with slight eastward flow at the surface $\left(156^{\circ} \mathrm{E}, 165^{\circ} \mathrm{E}\right)$, westward flow beneath, and the eastward EU at $150 \mathrm{~m}$ and deeper is well re- produced. It is interesting to point out that the inversion of the surface flow at the eastern edge of the warm pool is essential in maintaining the mean position of a salinity front there (Picaut et al. 1996; Vialard and Delecluse 1998b). Therefore, the model contains some of the essential surface current information.

Yet, there are some discrepancies between the model and data. The strength of the EU is systematically underestimated in the model (by 0.1 to $0.2 \mathrm{~m} \mathrm{~s}^{-1}$ ). As suggested in the previous section, the strength of the surface SEC is overestimated. Some improvement in 


\section{Zonal Current profiles at the Equator (Model/TAO)}

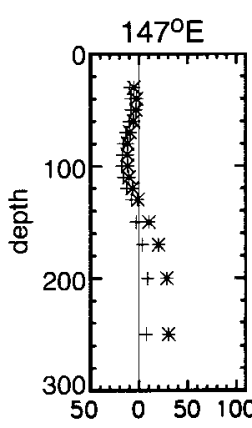

$156^{\circ} \mathrm{E}$
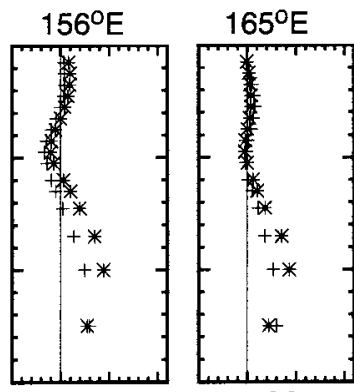

Mean Profiles
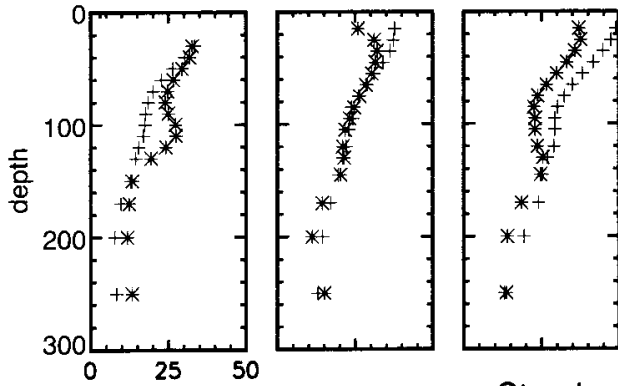

Standard Deviation
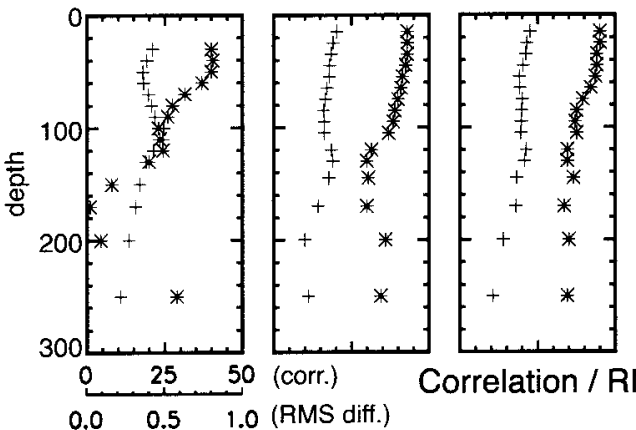
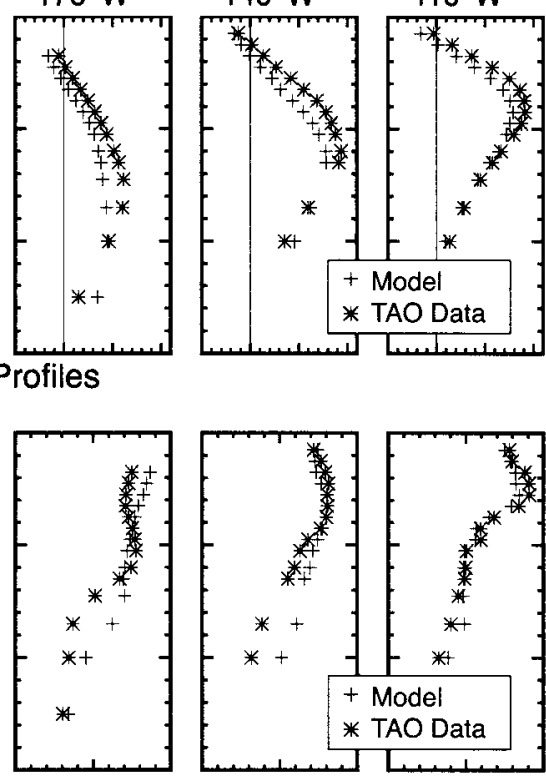

$140^{\circ} \mathrm{W}$
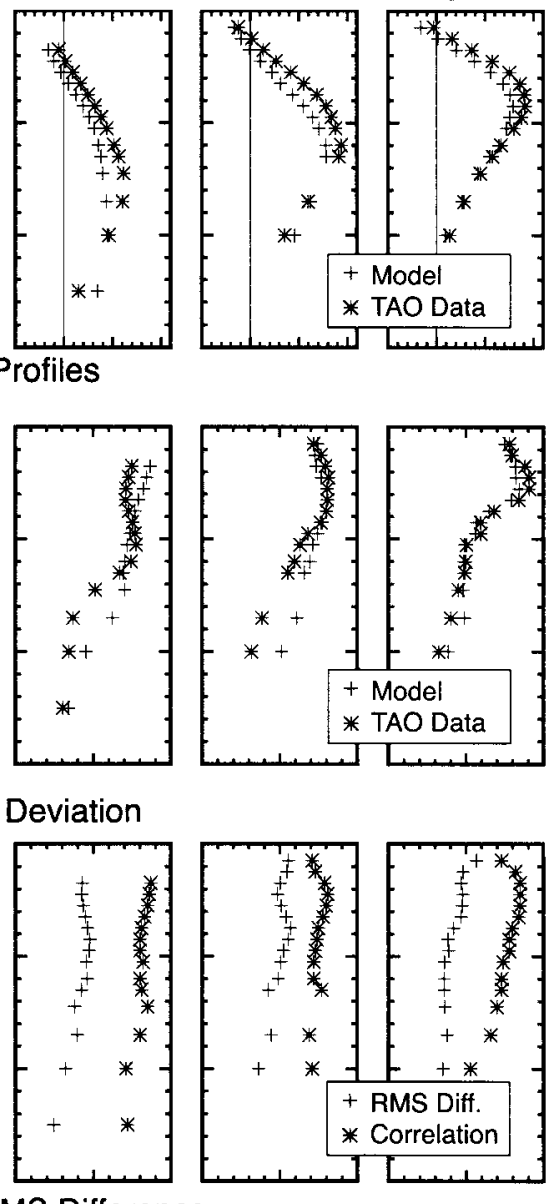

FIG. 6. Comparison between model and TAO currents along the equator at $147^{\circ} \mathrm{E}, 156^{\circ} \mathrm{E}, 165^{\circ} \mathrm{E}$, $170^{\circ} \mathrm{W}, 140^{\circ} \mathrm{W}$, and $110^{\circ} \mathrm{W}$.

accelerating the EU and decreasing the strength of the SEC can be brought by using isopycnal diffusion in the model rather than the horizontal diffusion used here (Lengaigne et al. 2000, unpublished manuscript).

The second and third horizontal panels of Fig. 6 show that the vertical structure of current variability is quite well reproduced by the model. However, the ERS + TAO run overestimates the amplitude of zonal currents near the surface at $156^{\circ} \mathrm{E}, 165^{\circ} \mathrm{E}$, and $170^{\circ} \mathrm{W}$. Yet, given good correlation between the model and observations (between 0.7 and 0.9 everywhere, except at $147^{\circ} \mathrm{E}$ below $75 \mathrm{~m}$ ), the sometimes quite large rms difference can mostly be explained by systematic biases. These correlation scores can be considered very good, given that the model and data are compared on a 5-day sample basis. In relation to previous results stressing the importance of wind forcing in the quality of simulations (Grima et al. 1999; Menkes et al. 1998), we think that the good model performance is related to the adequacy of the ERS + TAO wind stress forcing for equatorial simulations.

As far as currents are concerned, we have examined the vertical structure along the equator because TAO current mooring information is the only available information about currents at these latitudes and for these dates. This clearly stresses the need for additional in situ subsurface current information away from the equator if only for modeling purposes.

In summary, all of the comparisons presented here lead us to conclude that the ERS + TAO simulation exhibits good skill in reproducing the main observed features, both in terms of the mean state and variability. Because of this good agreement with observations, we can now turn confidently to the model analyses to investigate physical processes at work during the 199398 time period. We will particularly focus on the surface layer heat budget, as the SST is the key variable by which the ocean couples to the atmosphere. 


\section{The 1993-96 period}

The 1993-96 period is too short to undertake a rigorous study of the seasonal cycle in the model. The main objective of this section therefore is to provide an outline of the processes determining the SST seasonal cycle in the model. This description will help when trying to understand deviations from this equilibrium during the 1997-98 El Niño event. Section 4a gives an overview of the mean annual balance, and section $4 \mathrm{~b}$ describes qualitatively the annual cycle in the model.

\section{a. The mean SST balance}

Figure 7 shows the SST tendencies averaged over 1993-96 in the model (zonal and meridional advection by low frequency currents, eddies, subsurface tendency, forcing tendency; the climatological SST tendency is very close to zero and has not been plotted). In the eastern Pacific, the first-order balance involves heating by forcing and eddies and cooling by vertical processes at the mixed layer base. The eastern Pacific cold water is heated up by an average annual $100 \mathrm{~W} \mathrm{~m}^{-2}$ net flux into the ocean (e.g., Oberhüber 1988). This results in the pattern of warming by atmospheric fluxes seen in Fig. 7e. On the other hand, the cool water of the underlying thermocline (which is shallow in this region) tends to cool the surface water by entrainment, equatorial upwelling, and vertical diffusion. This cooling by subsurface processes is slightly meridionally asymmetric (Fig. 7d). This is because tropical instability waves (TIWs) are very active north of the equator (Fig. 7c). They are associated with strong values of the entrainment and the upwelling, which show up in this longterm average.

The predominance of forcing and subsurface cooling in the eastern Pacific in the model mean balance is in agreement with previous studies (Bryden and Brady 1989; Wang and McPhaden 1999). Like Hansen and Paul (1984), we however find that the eddy heat flux makes up for the imbalance between heat flux and subsurface cooling. We will now clarify why the effect of the eddy-induced horizontal advection, seen in Fig. 7c, results in net heating. Very strong values of eddy-induced advection occur in the region where the TIWs (Baturin and Niiler 1997) are the most active [note the striking similarity of the pattern in Fig. 7c and plate 4 in Baturin and Niiler (1997)]. Observational studies already noted that the TIW could cause the meridional advection to be a heating effect near the equator (e.g., Bryden and Brady 1989; Wang and McPhaden 1999). However, because of insufficient sampling of the zonal scale of these waves (which is about $1000 \mathrm{~km}$ ), their effect on zonal advection has not been well described. Our model compares well to observations in the TIW region (correlation to TAO 5-day surface currents is 0.75 at $110^{\circ} \mathrm{W}$ ) and has a 1 degree zonal resolution. We can thus look closer at the role of intraseasonal vari- (a) Zonal adv. by low-freq. currents

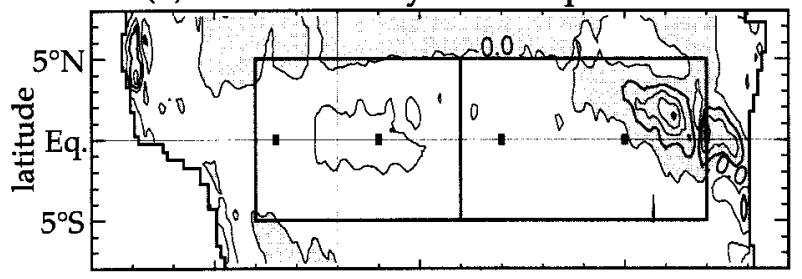

(b) Meridional adv. by low-freq. currents

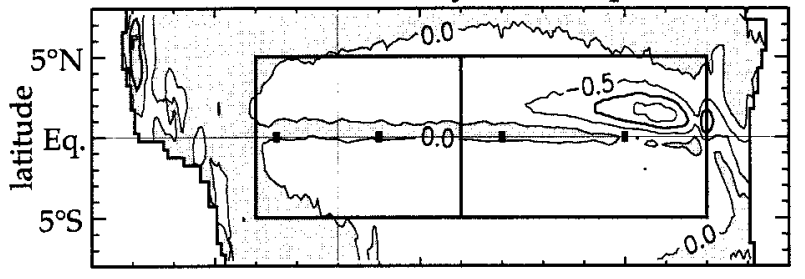

(c) Eddies

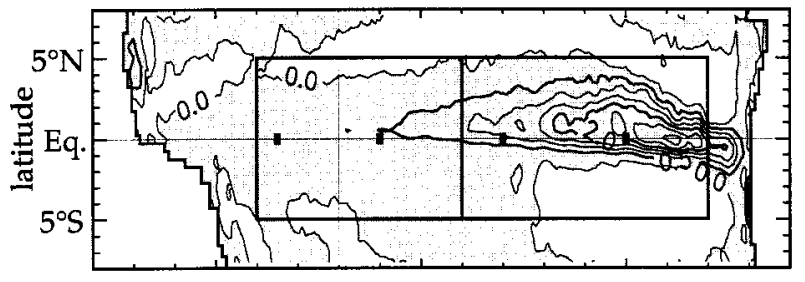

(d) Subsurface

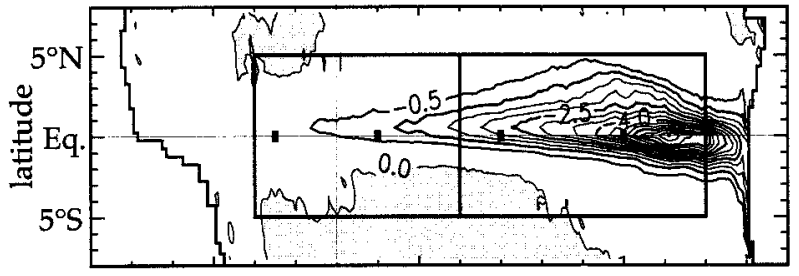

(e) Forcing

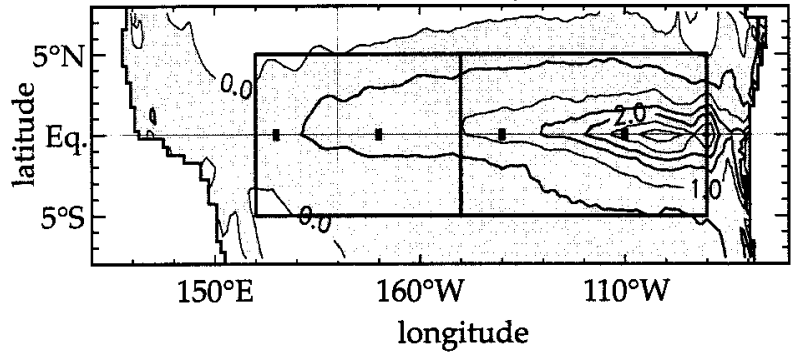

FIG. 7. Latitude-longitude plots of the 1993-96 average of the SST tendencies in the eastern Pacific: (a) zonal advection by low frequency currents, (b) meridional advection by low frequency currents, (c) eddies, (d) tendency due to vertical exchange with deep ocean, and (e) atmospheric forcing. Contours every $0.5 \mathrm{~K} \mathrm{month}^{-1}$; shading indicates warming tendencies.

ability on the surface layer heat budget. Figure 8 shows (a) a snapshot of the modeled SST and currents in December 1996, (b) the horizontal advection and the modeled currents at that date, and (c) the December 1996 
(a) SST for Dec. 15, 1996

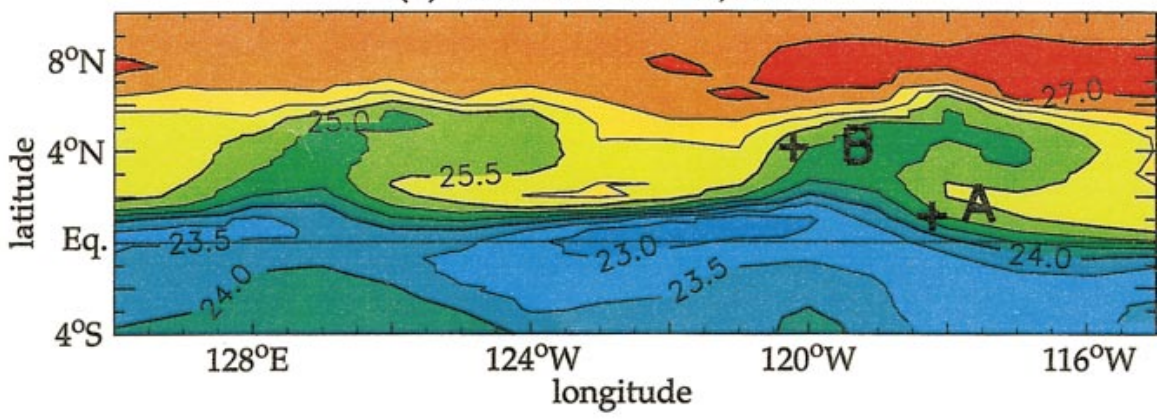

(b) Total horiz. adv., SST, currents for Dec. 15, 1996

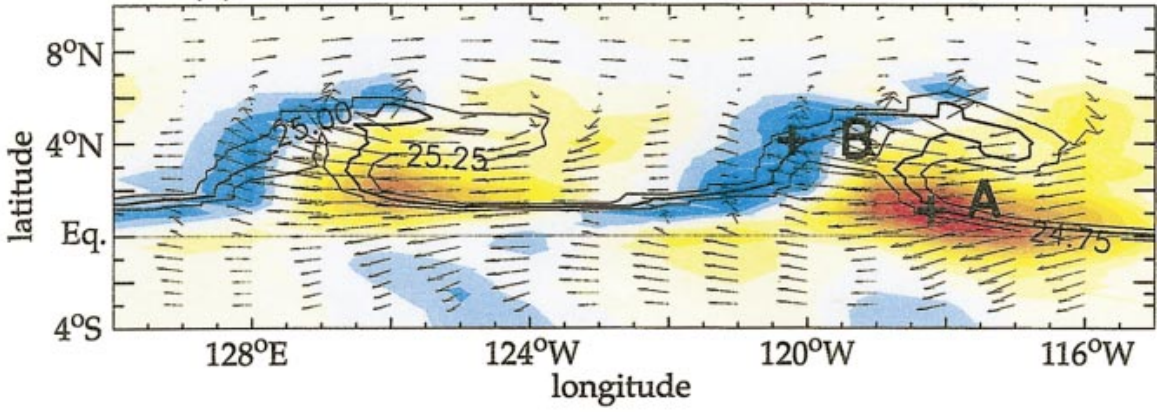

(c) Dec. 1996 monthly mean total horizontal advection

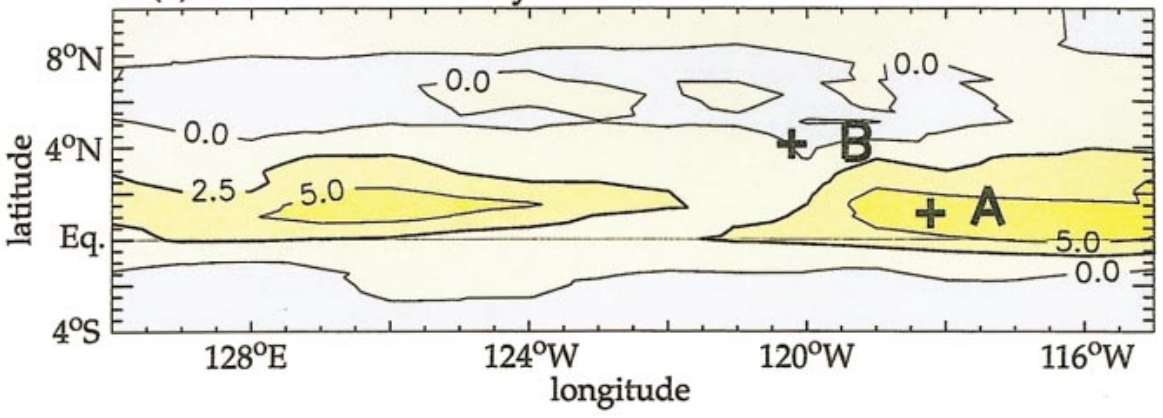

FIG. 8. Latitude-longitude plots of tropical instability waves in the ocean model: (a) SST for 15 Dec 1996 (contours every 0.5 K); (b) surface currents (vectors), SST (24.75, 25, and 25.25 contours) and total (e.g., low-frequency currents + eddies) horizontal advection (in $\mathrm{K}$ month ${ }^{-1}$, colors); (c) total horizontal advection averaged over Dec (contours every $2.5 \mathrm{~K} \mathrm{month}^{-1}$ ).

monthly mean picture of horizontal advection. The TIW in Fig. 8a displays the same qualitative features as in observations (Flament et al. 1996; Kennan and Flament 2000) and as in a previous model study (Kennan and Flament 2000): the flow is anticyclonic, northward in the cold cusp and southward in the warm cusp. The TIW flow strongly crosses isotherms at the points indicated by $\mathbf{A}$ and $\mathbf{B}$. The east-west flow is downgradient near $\mathbf{A}$ and upgradient near $\mathbf{B}$. This results in a very strong positive heating near $\mathrm{A}\left(\sim 20^{\circ} \mathrm{C}\right.$ month $\left.^{-1}\right)$ and a cooling near $\mathbf{B}\left(\sim-10^{\circ} \mathrm{C} \mathrm{month}^{-1}\right)$. This pattern is moving in time as the eddies propagate. When considering a monthly mean of these advection terms (Fig. 8c), this results in a warming tendency $\left(\sim 5^{\circ} \mathrm{C}\right.$ month $\left.{ }^{-1}\right)$ from the equator to $5^{\circ} \mathrm{N}$ and a slight cooling tendency at $5^{\circ}-$ $6^{\circ} \mathrm{N}$. This explains why the 1993-96 eddy-induced ad- vection term has the shape seen in Fig. 7c. In fact, the eddies result in a strong positive contribution of zonal advection from the equator to $4^{\circ} \mathrm{N}$ (figure not shown). Similarly, this results in a tripole pattern of meridional advection (negative at $2^{\circ} \mathrm{N}$, positive at the equator, and negative at $2^{\circ} \mathrm{S}$, figure not shown). This last effect is observed from observations in the study of Wang and McPhaden (1999). This strong impact of instability waves on the surface layer heat budget is a robust feature of the model: it appears when using different forcing products, or even in coupled mode, with a climatic state very different to the observed one (Vialard 1997).

Zonal and meridional advection by the low-frequency currents contribute little to the mean balance in the eastern Pacific (Figs. 7a and 7b). The meridional advection pattern is a cooling North of the equator in the eastern 

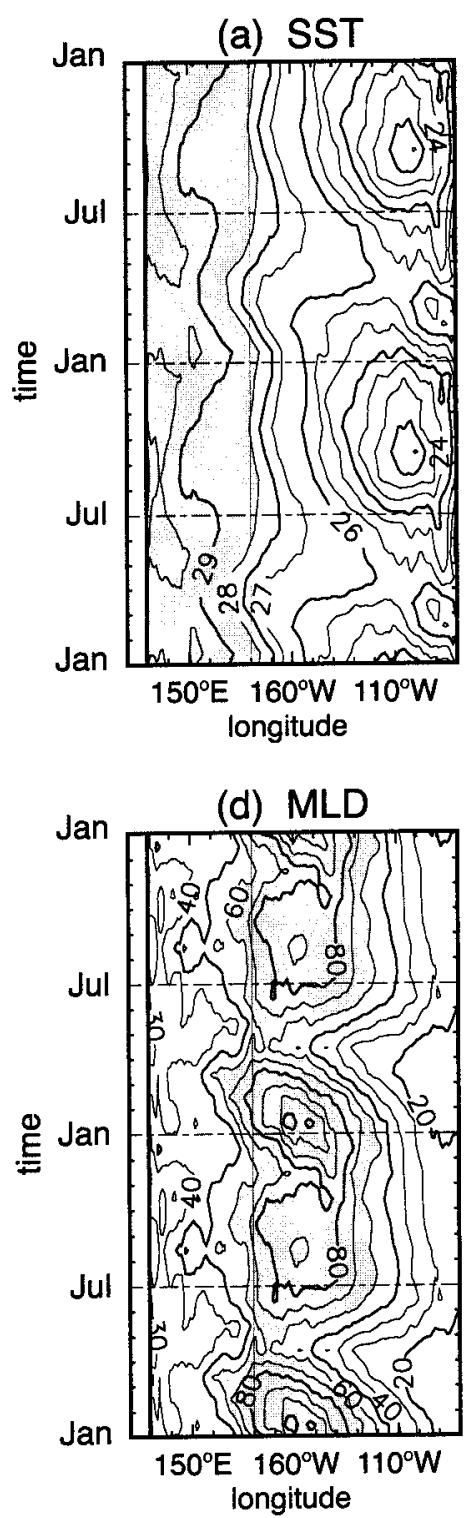

(b) D20 (anomaly)

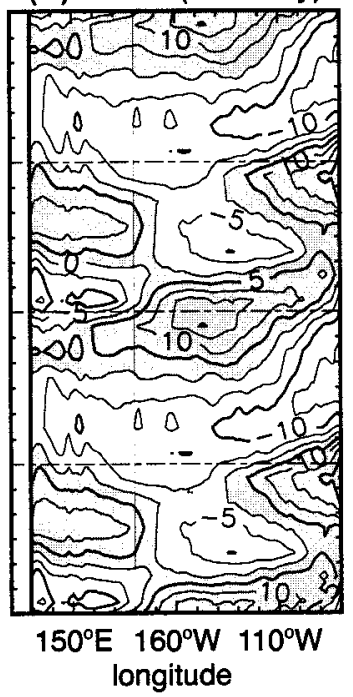

(e) $\tau_{x}$

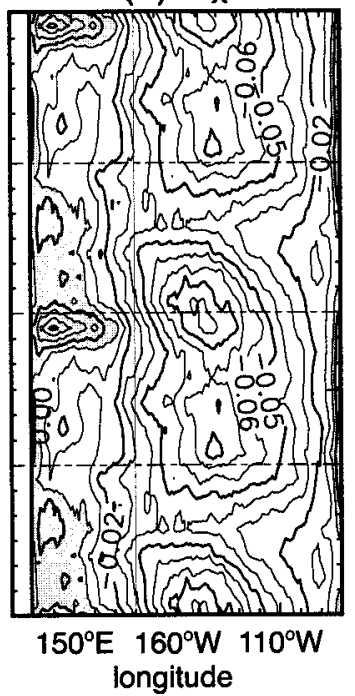

FIG. 9. Time-longitude diagram along the equator of two 1993-96 average seasonal cycles: (a) SST (contours every $1 \mathrm{~K}$, shading above $28^{\circ} \mathrm{C}$ ); (b) depth of the $20^{\circ} \mathrm{C}$ isotherm (anomaly with respect to the 1993-96 average, contours every $5 \mathrm{~m}$, shading indicate positive values); (c) zonal current at $5 \mathrm{~m}$ (contours every $0.1 \mathrm{~m} \mathrm{~s}^{-1}$, shading indicate eastward flow); (d) mixed layer depth (contour every $10 \mathrm{~m}$, shading for values above $60 \mathrm{~m}$ ); and (e) zonal wind stress (contour every $0.01 \mathrm{~N} \mathrm{~m}^{-2}$, shading indicate eastward wind).

Pacific. That is indeed the region where the poleward flow due to equatorial divergence (see Fig. 5) meets the tight gradient between the cool water of the eastern $\mathrm{Pa}$ cific and the warm water from the NECC. Note that the zonal advection (Fig. 7a) positive pattern north of the equator in the eastern Pacific happens in a region where the model north equatorial SST front bends too much southward compared to Reynolds data: this pattern may thus be spurious or much too strong in the model.

The zonal advection by low frequency currents (Fig. $7 a)$ is slightly negative in the central and western Pacific, due to the SEC penetration in the warm pool, bringing colder water from the east. In this region, the balance is more complex than in the eastern Pacific. The main balance is warming by surface fluxes (Fig. 7e), compensated by cooling by zonal advection by low frequency currents and subsurface processes.

\section{b. The seasonal cycle}

Figure 9 displays the evolution of the modeled 199396 average of the seasonal cycle in $2^{\circ} \mathrm{N}-2^{\circ} \mathrm{S}$. The main 
(a) Niño 4

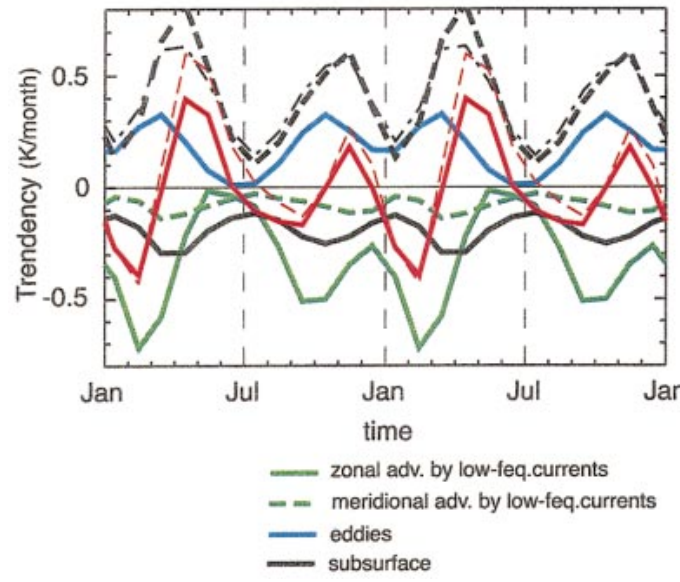

(b) Niño 3

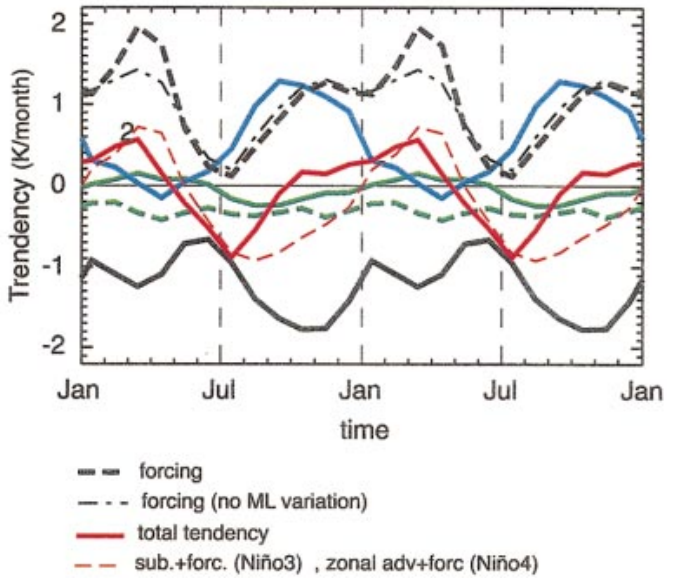

FIG. 10. Two 1993-96 average seasonal cycles of the SST tendencies in the model: (a) in Niño-4 and (b) in Niño3. Note the difference of scaling of the vertical axis for (a) and (b). The zonal advection by low frequency currents is in green. The meridional advection by low frequency currents is in dashed green. The effect of eddies is in blue. The subsurface tendency is in black. The atmospheric forcing tendency is in dashed black (dot-dashed black is the same tendency computed when not accounting for the effect of mixed layer depth variations). The total SST tendency is in red. The dashed red curve is a rough estimate of the mean balance in each box (subsurface + forcing for the Niño-3 box, zonal advection by low-frequency currents + forcing in Niño-4).

dynamical features of the observed seasonal cycle (Yu and McPhaden 1999) are reproduced by the ocean model. Figure 10 gives the time evolution of the 1993-96 seasonal cycle of the SST tendencies, averaged in Niño$3\left(5^{\circ} \mathrm{S}\right.$ to $5^{\circ} \mathrm{N}, 90^{\circ} \mathrm{W}$ to $\left.150^{\circ} \mathrm{W}\right)$ and Niño-4 $\left(5^{\circ} \mathrm{S}\right.$ to $5^{\circ} \mathrm{N}, 150^{\circ} \mathrm{W}$ to $160^{\circ} \mathrm{E}$ ). Note that, as damping toward the observed seasonal cycle is used in the model formulation, the following description should be considered as qualitative, rather than quantitative, since the damping term might sometimes work to compensate for model deficiencies. Given the generally good agreement between the model and observations described in previous sections though, we expect however the model heat balance to be reasonably representative of what happens in the real ocean.

As in Fig. 7, the three strongest terms in the Niño3 budget are the subsurface cooling effect, the eddy warming, and surface heating effects (Fig. 10b). Cooling by low-frequency meridional advection is small while the effect of the low-frequency zonal advection is always negligible. The SST variation is mostly annual, with a warming tendency from October to April. It is highly correlated with the forcing tendency (term 4 in Eq. (2), black dashed curve), which varies primarily because of the incoming surface heat flux (with strongest heating occurring from October to April). The effect of mixed layer depth variations, though of second order, is not negligible (the black dashed-dotted curve corresponds to term 4 in Eq. (2), computed with the climatological mixed layer depth value). The shallow mixed layer associated to weak wind favors the surface layer heating in March-April when the SST peaks (Fig. 9). The subsurface tendency (entrainment, vertical advection and vertical mixing, black curve) is strongly correlated to the depth of the thermocline (e.g., the distance from the surface to the underlying cold thermocline water). Indeed, the cooling has two relative maxima in February-March and October-November (Fig. $10 \mathrm{~b}$ ), which correspond to the semiannual shoaling of the thermocline in the east (Fig. 9b). Conversely, the cooling by subsurface processes diminishes when the thermocline moves down, most notably in May-June. The balance between heating by atmospheric forcing and cooling by subsurface processes is essential to maintain SST variations in the Niño-3 region. This can be seen when looking at the sum of these two terms as depicted in dashed red. To first order, these two terms explain most of the SST seasonal variation from February to July. This is the period when eddy-induced horizontal advection is the weakest (blue curve). During July and August, associated with the northward position of the intertropical convergence zone, the easterlies strengthen in the eastern equatorial Pacific (Fig. 9e). As a result, the equatorial currents speed up, and the equatorial tongue cools down (Figs. 9a and 9c). This is the period when instability waves become very active (Baturin and Niiler 1997), as the result of increased meridional temperature gradient and shear between the SEC and NECC or between SEC and EU. As we saw in the previous section, active TIWs result in quite strong heating values of the eddy contribution to advection from the equator to $4^{\circ} \mathrm{N}$. The result is the strong positive values in Niño-3 from August to December (blue curve in Fig. 10b). The effects of tropical instability waves must clearly be accounted for during this period to close the surface-layer heat budget. Finally, the meridional advection by low frequency currents (green dashed curve in Fig. 10a) always contributes as 
a cooling, as we explained in the previous section, and varies only weakly during the year. The zonal advection by low frequency currents (green curve in Fig. 10a) is quite weak, and varies in phase with the SEC.

In the central and western Pacific (Niño-4), tendencies are generally much weaker and the balance is more complex. The semiannual component of SST variability is evident in the western Pacific, with a positive tendency in both April-June and October-December. Here, meridional advection by low frequency currents (green dashed curve in Fig. 10a) contribute little to the total budget. The major sources of seasonal SST variability in the central and western Pacific come from surface heat flux forcing (black dashed curve) and zonal advection by low frequency currents (green curve). The semiannual cycle of surface heat flux forcing comes from the movements of the sun that crosses the equator twice a year. As in the eastern Pacific, the thin mixed layer contributes to slightly higher values of the SST in March-May by trapping the fluxes in the surface layer. Zonal advection closely follows the SEC strength cycle in the western Pacific. During May-August, the SEC weakens (and even reverses) in the central and western Pacific (Fig. 9c), leading to a reduction of cold water advection from the east. In contrast, cooling is increased in February-March and September-October, when the SEC penetrates more in the western Pacific (Fig. 9c; Reverdin et al. 1994). The cooling effect of zonal advection is significant but partly compensated by heating by eddy fluxes (blue curve). This heating has two maxima, with the one in October linked to the active TIW period in the eastern Pacific. The other in March is certainly due to increased activity of TIWs in the model in the central Pacific at this period, linked to the increase of the shear between the SEC and NECC. Cooling by subsurface processes is still anticorrelated to surface forcing, but has a weaker effect than in the eastern Pacific.

The overall mean balance of the seasonal cycle is thus quite similar to the one described for the mean state (forcing, subsurface tendency, and eddies in the eastern Pacific, whereas zonal advection becomes more important in the central Pacific).

\section{The 1997-98 El Niño}

Now that we have investigated the basic equilibrium at work in the model mean state and seasonal cycle, we can investigate the rise and fall of the large SST anomalies associated to the 1997-98 El Niño. We first describe in section 5a which oceanic mechanisms can change SST tendency from its mean seasonal cycle. We then proceed to a detailed chronology of the main causes of the SST anomalies during the 1997-98 El Niño in section $5 \mathrm{~b}$.

\section{a. Interannual anomalies in the surface-layer heat budget}

Figure 11 shows the interannual anomalies (with respect to the 1993-96 seasonal cycle) of the processes contributing to the surface layer heat budget during 1996-99, averaged in Niño-4 and Niño-3 (Figs. 11c and 11d). In Figs. 11a and 11b, the interannual SST and seasonal cycle of the model and observations have also been plotted to show that, despite offsets, the qualitative features of the SST evolution have been captured by the model. Figure 12 shows a time-longitude section along the equator of SST, zonal wind stress, and depth of the $20^{\circ} \mathrm{C}$ isotherm interannual anomaly, as well as zonal current, mixed layer depth, and SST.

In Niño-3, one sees that the SST tendency (red curve) is relatively small compared to other tendencies. This illustrates the delicate balance between the different tendencies. The SST tendency is positive from January 1997 to December 1997 when the El Niño peaks. This results in growing SST anomalies, as observed. During that time period, the budget shows how the reduced cooling tendency by subsurface processes (black curve, Fig. 11c) is essential to the heating of the eastern Pacific. In the seasonal cycle, reduced cooling by subsurface processes develops when the thermocline is deepening (see previous paragraph). Similarly here, positive anomalies of the subsurface tendency tend to develop when the thermocline is deepening (e.g., in 1997; thick black curve in Figs. 11d and 12c). Negative anomalies of subsurface processes can happen under the combined effect of a shallow thermocline and strong SEC (e.g., at the end of 1998, Figs. 12c and 12d). The increased equatorial divergence then leads to increased upwelling of subsurface cold water (at the end of 1998, black curve in Fig. 11d).

These very strong variations of the subsurface tendencies during El Niño are partly balanced by the surface forcing (thick dashed black curve, Fig. 11d), here very simply parameterized as a relaxation toward climatological temperatures. Indeed, in nature, as soon as El Niño develops, warmer than usual SST in the east leads to a reduction of surface fluxes. The heating by atmospheric forcing is lower than usually at the same season, damping the growth of the interannual anomaly. This subsurface-forcing balance is reversed during $\mathrm{La}$ Niña.

The effect of eddies (blue curve, Fig. 11d) is also perturbed during an ENSO. It is anticorrelated to the SST tendency. The reader should recall (section 4) that TIW are contributing strongly to the positive values of the eddy effects on temperature advection. During an El Niño, tropical instability wave activity is much weaker due to diminished shear between the SEC and NECC and diminished meridional temperature gradients $(\mathrm{Ba}-$ turin and Niiler 1997). As a result, they bring much less heat to the tropical band than usual. This is why the eddy tendency appears as a negative contribution (cool- 
(a) Niño 4 SST

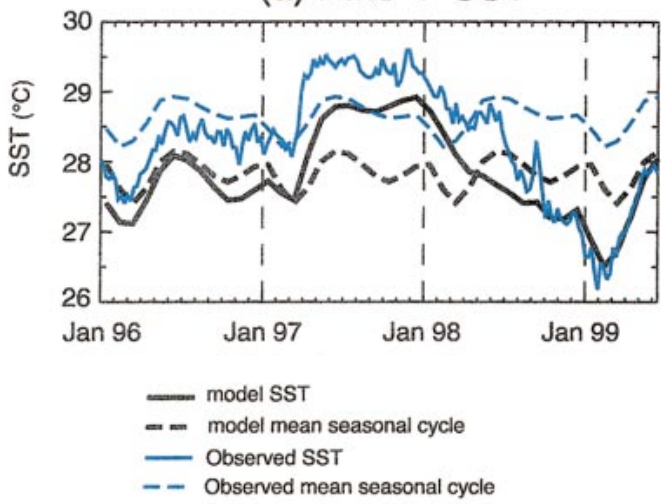

(c) Niño 4

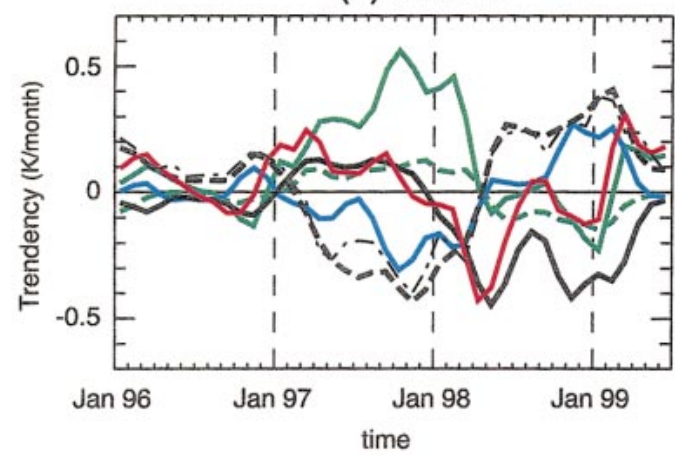

_ zonal adv. by low-feq.currents

- - meridional adv. by low-feq.currents

- eddies

- subsurface (b) Niño 3 SST

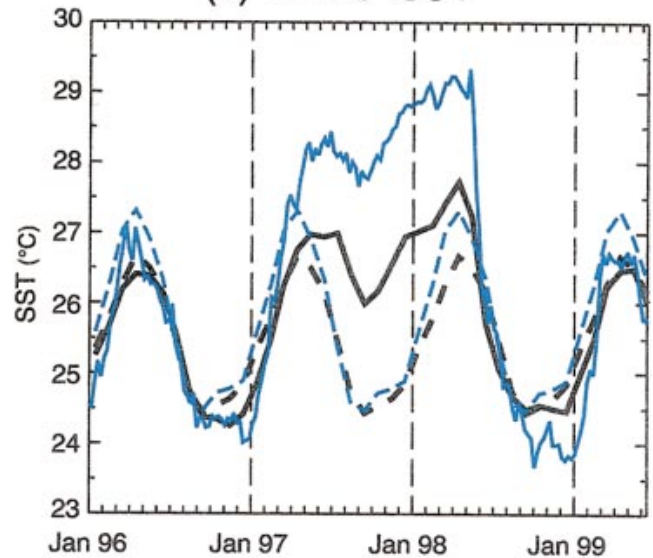

(d) Niño 3

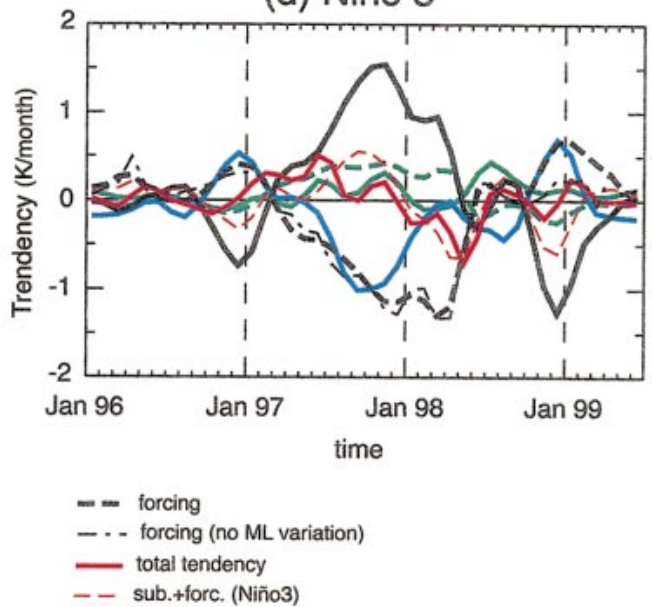

FIG. 11. Time-longitude diagrams of modeled (black) and observed (blue) SST (full line) and SST seasonal cycle (dashed line) in Niño-4 (a) and Niño-3 (b). Time-longitude diagrams of SST tendencies interannual anomalies for 1996-99 in Niño-4 (c) and Niño-3 (d). Note the difference of scaling of the vertical axis for (c) and (d). The interannual anomalies are computed with respect to the 1993-96 average. The color code is similar to the one in Fig. 10. The estimate of the mean balance (dashed red curve) is the subsurface + forcing tendencies in Niño- 3 but is not shown in Niño-4 since it is more complex there (see text). A temporal 1/4-1/2-1/4 filter on monthly values was applied.

ing) to the El Niño growth in the eastern Pacific. Throughout the El Niño (from March 1997 to May 1998), the eddy tendency is markedly negative, acting as a negative feedback to the growth of the El Niño, together with the heat flux.

The interannual anomaly of meridional advection by low frequency currents (dashed green curve, Fig. 11d) is positive during 1997. Indeed, during El Niños, the meridional temperature gradient between the equator and the NECC strongly diminishes, and so does the effect of cooling by meridional advection. Conversely, there is no marked increase of the cooling by meridional advection from low frequency currents during La Niña. The interannual fluctuations of zonal advection by low frequency currents are weak in the eastern Pacific.

In agreement with (Picaut et al. 1996; Picaut et al. 2001), we find that zonal advection by low frequency currents plays a clear role in the western and central Pacific (green curve, Fig. 11c). This is mainly due to the development of eastward current anomalies in the western and central Pacific during El Niño, which drive the warm pool eastward.

This effect of zonal advection on the heat budget is partly compensated by forcing. As previously mentioned, the interannual net heat fluxes tend to decrease when the interannual SST rises [Eq. (1)], thus leading to a relative cooling. The subsurface interannual anomaly tendency can also become important in the western Pacific, especially during La Niña when the cold tongue regime extends to the west (Fig. 11c, black curve).

\section{b. Chronology of the event}

Interannual anomalies of the tendencies were presented in the previous section to better describe the dis- 
(a) SST (anomaly)

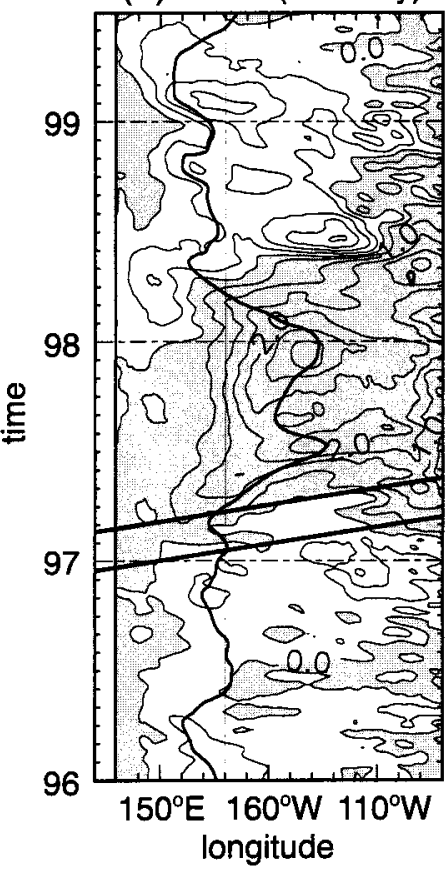

(d) $U_{5 m}$

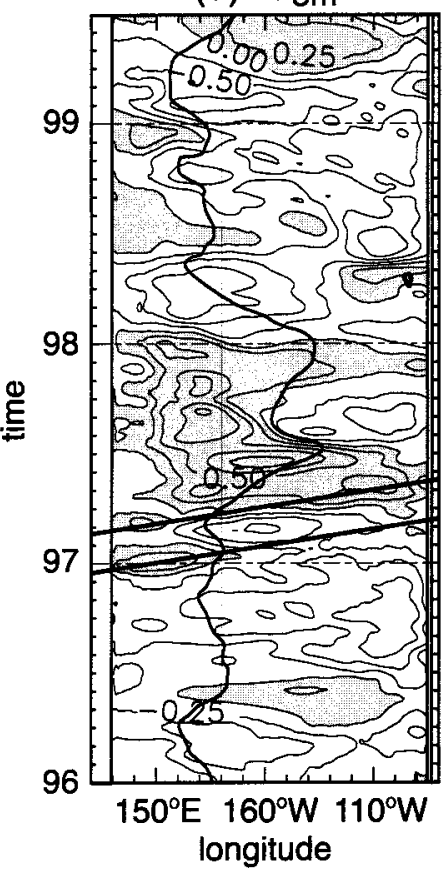

(b) $\tau_{\mathbf{x}}$ (anomaly)

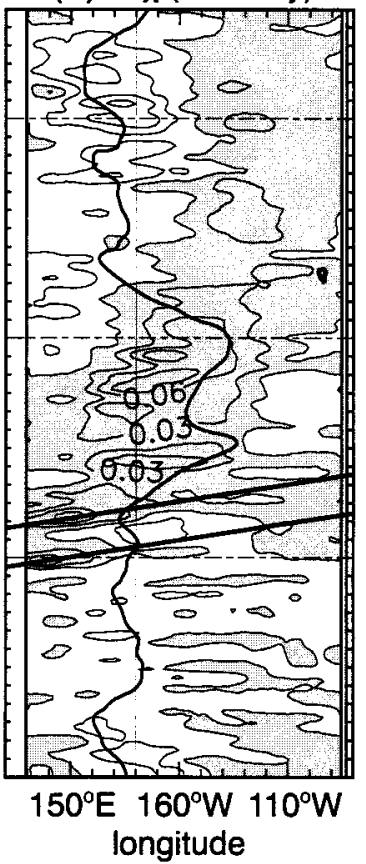

(e) MLD

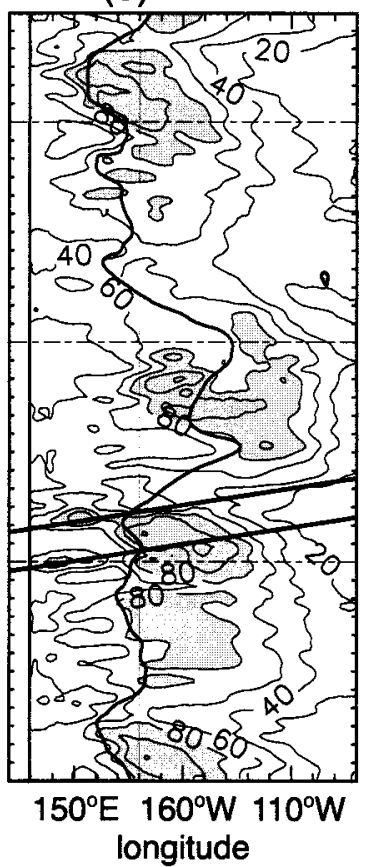

(c) D20 (anomaly)

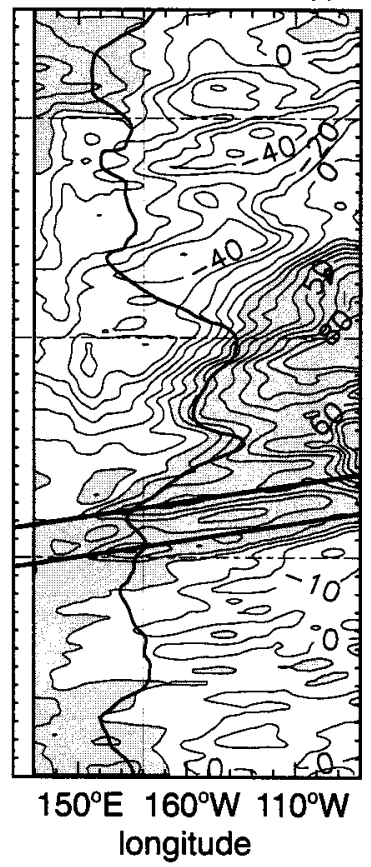

(f) SST

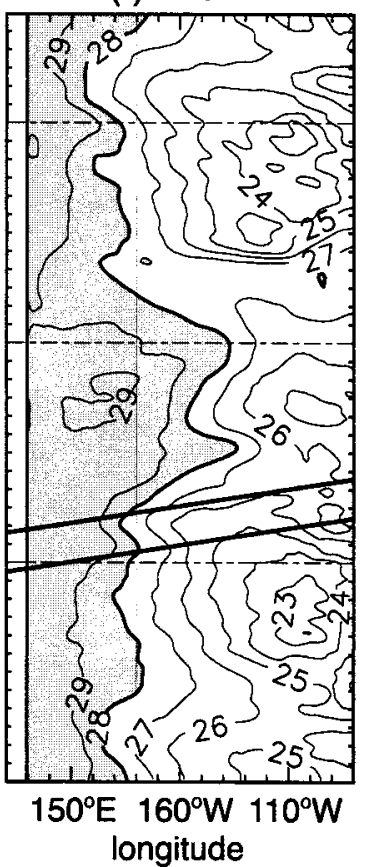

FIG. 12. Jan 1996 to Jun 1999 time-longitude diagrams along the equator: (a) SST (anomaly with respect to the 1993-96 seasonal cycle, contour $0.5 \mathrm{~K}$, shading for positive anomalies); (b) Wind stress (anomaly with respect to the 1993-96 seasonal cycle, contour $0.03 \mathrm{~N} \mathrm{~m}^{-2}$, shading for positive anomalies); (c) depth of the $20^{\circ} \mathrm{C}$ isotherm (anomaly with respect to the 1993-96 seasonal cycle contour $5 \mathrm{~m}$, shading for positive anomalies); (d) zonal current at $5 \mathrm{~m}$ (contour $0.25 \mathrm{~m} \mathrm{~s}^{-1}$, shading for eastward currents); (e) mixed layer depth (contour $20 \mathrm{~m}$, shading for values above $80 \mathrm{~m}$ ); and (f) SST (contour every $1 \mathrm{~K}$, shading for values above $28^{\circ} \mathrm{C}$ ). The heavy black line denotes the $28^{\circ} \mathrm{C}$ isotherm. A temporal $1 / 4-1 / 2-1 / 4$ filter on pentad values and a 5 moving average zonal filter were applied. 
ruption of the seasonal cycle during an El Niño. However such a view can be restrictive, or even misleading, especially during a strong event. For example, after June 1997, the thermocline became so deep in the eastern Pacific that the total subsurface tendency was close to zero, and remained so until March 1998. The increase of the interannual anomaly of the subsurface tendency during 1997 (Fig. 11d) was thus only the result the subtracted seasonal cycle. For this reason, we have chosen to also describe the evolution of the 1997-98 El Niño in terms of total fields. Figure 13 shows the total surface temperature tendencies (zonal and meridional advection by low frequency currents, eddies, subsurface, forcing, and total SST tendency along the equator for October 1996-June 1999).

At the end of 1996, the warm pool is confined to the far western Pacific and has a higher than usual heat content. Unusually warm water occupies the first 150 $\mathrm{m}$ in the warm pool (with subsurface anomalies reaching about $1.5 \mathrm{~K}$ at $100 \mathrm{~m}$ depth, as in the observations; figure not shown). In contrast, in the central-eastern Pacific, cold anomalies (about $-1 \mathrm{~K}$ ) are found in the upper $150 \mathrm{~m}$. This situation is associated with stronger than usual easterlies in the central Pacific (lasting until the beginning of March, Fig. 12b). This results in stronger than usual subsurface cooling in the eastern Pacific in September-December (Figs. 11d and 13), partly compensated by eddies and forcing (Figs. 11d and 13). In the central-western Pacific, the stronger than normal SEC contribute to maintain the eastern edge of the warm pool to the west (note the slightly negative value of zonal advection in September-December, Figs. 12d and 13a). This first phase (until February 1997) is thus characterized by an intensification of the seasonal cycle, resulting in an enhanced cold tongue.

Associated with enhanced Madden-Julian oscillations, a series of strong westerly wind bursts (WWBs) then occur (e.g., McPhaden 1999; Boulanger and Menkes 1999). The first one is near $150^{\circ} \mathrm{E}$ in December 1996 (Fig. 12b). It forces a brief eastward surface current jet (Fig. 12c) that advects the warm pool slightly eastward, but this tendency is quickly counteracted by reinforced easterlies in the central Pacific (Fig. 12b) and associated westward currents (Fig. 12d). The warm pool moves back westward in February-March as a result of enhanced zonal advection of cold water (Fig. 13a). The downwelling Kelvin wave generated by this wind burst reaches the eastern Pacific at the end of February. Together with the weak westerly anomalies that have appeared in this region since January (Fig. 12b), it contributes to deepen the thermocline (Fig. 12c). This modifies the surface-layer heat budget, primarily by diminishing the subsurface cooling (Fig. 13d, black thick curve in Fig. 11d). This starts to weaken the equatorial cold tongue. But it will take the very strong March WWB to start again the warm pool progression toward the east and deepen the thermocline enough in the east to really warm the cold tongue. This event is very strong (with a 15 day duration and $0.15 \mathrm{Nm}^{-2}$ amplitude). The mixed layer deepens by more than $40 \mathrm{~m}$ in a few days in the forcing region. Eastward currents associated with a strong downwelling Kelvin wave propagate eastward (Figs. 12c and 12d). It is worth noting that the strong local deepening of the mixed layer, however, limited the impact of the wind burst in terms of currents. Indeed, the $0.4 \mathrm{~m} \mathrm{~s}^{-1}$ eastward zonal current that develops is not as strong as the $0.8 \mathrm{~m} \mathrm{~s}^{-1}$ eastward current that appears around $160^{\circ} \mathrm{W}$ in June 97 in the presence of weaker wind anomalies but a shallower mixed layer. Associated with these eastward currents, positive zonal advection tendencies appear in the central and western Pacific (Figs. 11 and 13a). This drives the eastward migration of the warm pool until the end of June (Figs. $12 \mathrm{f}$ and 13a). The important role of zonal advection in the central Pacific is consistent with the results of Boulanger and Menkes (2000) and Lagerloef et al. (1999). The three consecutive WWBs (December 1996, March 1997, and June 1997) were essential in setting the surface currents that drove the warm pool to $140^{\circ} \mathrm{W}$.

Meanwhile, in the eastern Pacific the second downwelling Kelvin wave adds to the effect of the previous one on the SST evolution. Cooling by local vertical processes is quickly completely suppressed (Fig. 13d). With it, the cold tongue progressively disappears. A consequence of this is a decrease of its associated meridional transport of cold water (see the meridional advection, Figs. 11d and 13b) and TIW heat transport (the eddy heating in suppressed, Fig. 13c). With the SST in the eastern Pacific beginning to rise above its normal values (Fig. 12a), the atmospheric fluxes also begin to act as a negative feedback (Fig. 13e) as can be expected from the simple formulation of the surface fluxes we are using [Eq. (1)]. Associated with these conditions (suppressed subsurface cooling in the east, strong positive zonal advection in the western and central Pacific), the warm anomalies amplify until June. The suppression of the subsurface cooling is the main cause of the temperature rise in the eastern Pacific. During all of this period, the budget is thus dominated by the role of the Kelvin waves excited by the WWBs. We will label this phase as the westerly wind burst phase (March-June).

At the beginning of June, a weak easterly wind anomaly starts to develop in the eastern Pacific (Fig. 12b). This wind anomaly might be a slightly delayed development of the seasonal cycle of winds due to the growing disruption in the coupled system. It might also be associated to a strengthening of the Hadley cell due to the warm anomaly developing near the equator. Its effect is to slightly raise the thermocline, and thus restore some subsurface cooling (Fig. 13d). The total SST drops slightly. This phase can thus be seen like a temporary (and delayed) reactivation of the seasonal cycle in the east.

In the west and central Pacific, the effect of the increased westward currents associated with these weak easterly wind anomalies is to drive the warm pool 2000 
(a) Zonal adv. by low-freq. currents

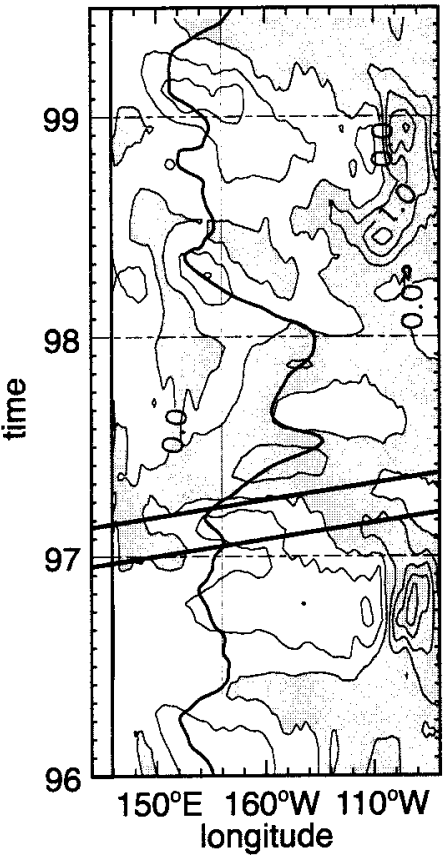

(d) Subsurface

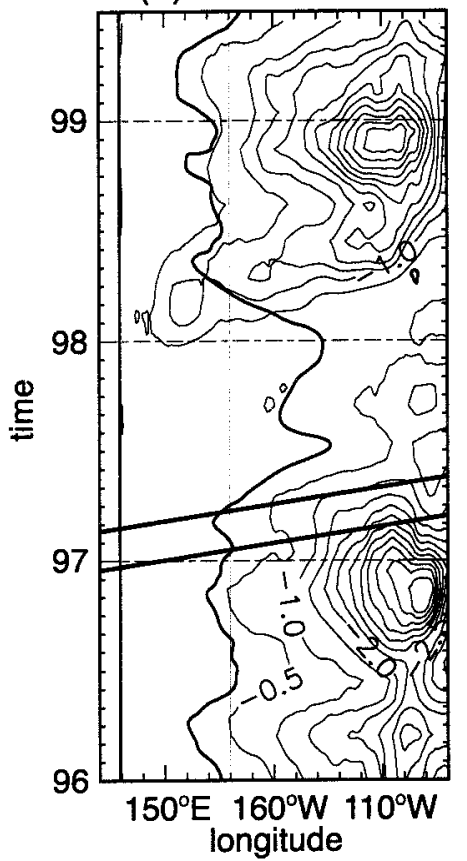

(b) Merid.adv. by low-freq. currents

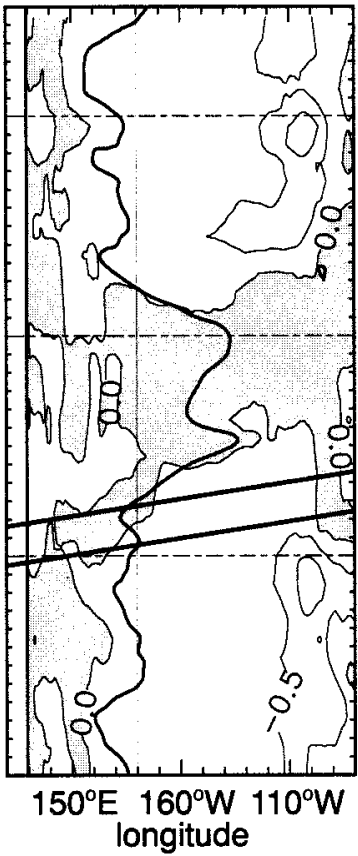

(e) Forcing

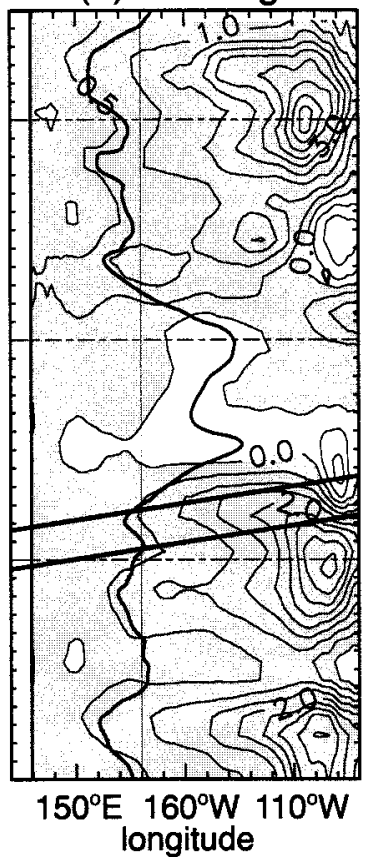

(c) Eddies

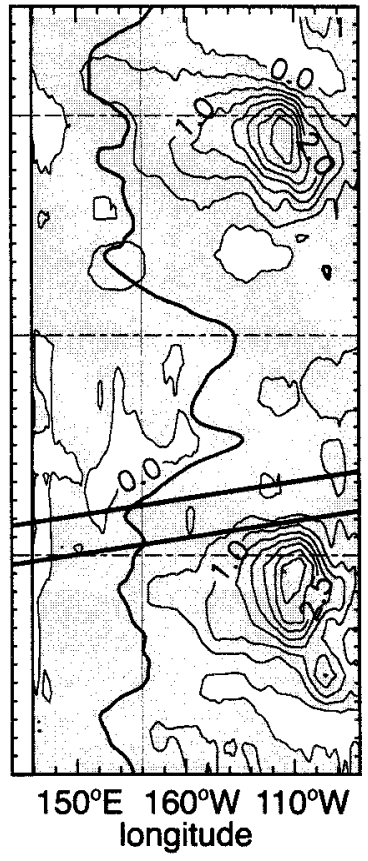

(f) Total tendency

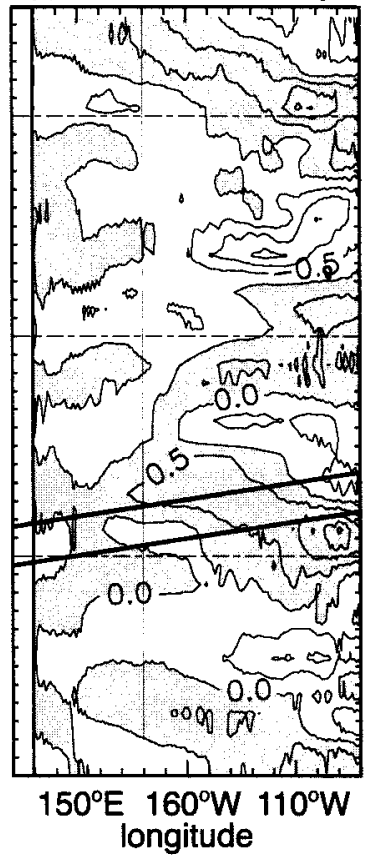

FIG. 13. Jan 1996 to Jun 1999 time-longitude diagrams of SST tendencies along the equator: (a) zonal advection by low frequency currents, (b) meridional advection by low frequency currents, (c) eddies, (d) subsurface effect, (e) atmospheric forcing, (f) total SST tendency. Contour every $0.5 \mathrm{~K}$ month ${ }^{-1}$, shading for warming tendencies. The heavy black line denotes the $28^{\circ} \mathrm{C}$ isotherm. A temporal $1 / 4-1 / 2-1 / 4$ filter on monthly values and a 5 moving average zonal filter were applied. 
km back via zonal advection (Figs. 12d and 13a). Shortly after this event, however, large-scale westerly wind anomalies appear in the central and western Pacific (Fig. $12 \mathrm{~b}$ ), and will persist for several months. Once again, zonal advection by low frequency currents is instrumental to this phase. Large-scale current anomalies (Fig. $12 \mathrm{~d}$ ) drive the $28^{\circ} \mathrm{C}$ isotherm to $140^{\circ} \mathrm{W}$. This phase is characterized by slow propagation of the wind anomaly/ zonal current anomaly/SST anomaly toward east. Meanwhile, the eastward propagating Kelvin downwelling waves, together with eastern boundary reflected Rossby waves (Boulanger and Menkes 1999, 2000), maintain a deep thermocline and high surface temperature in the eastern equatorial Pacific in early 1998.

At the end of 1997, while El Niño peaks in the eastern Pacific, large-scale easterly wind anomalies [a consistent feature in past El Niños (McPhaden 1999; Rasmusson and Carpenter 1982)] develop in the western Pacific. These wind anomalies are associated with offequatorial SST anomalies (Wang and Weisberg 2000) and are responsible for most of the thermocline rise that propagates slowly eastward (Fig. 2; Fig. 12c; Yu and McPhaden 1999), along with upwelling Kelvin waves reflected at the western boundary (Boulanger and Menkes 2000). These easterly anomalies are also the cause of the strong westward currents that develop in all the Pacific from January 1998 onward (Fig. 12d). In the central Pacific, these currents drive the $28^{\circ} \mathrm{C}$ isotherm back west. In the western Pacific, associated with the shallow thermocline (Fig. 12c), they generate upwelling that results in a cooling of the surface (Figs. 12f and 13d). In May, a short-lived intensification of the easterlies entrain cold water from the now much shallower thermocline and switch on very abruptly subsurface cooling in the eastern Pacific (Fig. 13d). The SST will rapidly fall, soon switching on again the processes associated with the cold tongue (cold water export by meridional advection, heat import by eddies, warming by the atmospheric fluxes: Fig. 13). However, weak easterlies will still persist for some months, and the eastern Pacific cooling will relax for a while. Then, associated with persistent cold anomalies in the east, easterlies intensify to lock the system in a La Niña state.

\section{Summary, discussion, and conclusions}

\section{a. Summary}

As a result of TOGA, models and observation networks have greatly improved over the last few years. The tropical Pacific Ocean is now well monitored, with both in situ and remote observations available in near real time. It is thus timely to assess the presumed improvements in ocean models by extensive validation against these observations. In the present study, a tropical Pacific version of the LODYC OGCM is validated against TOPEX/Poseidon altimetry, TAO in situ temperature and currents, Reynolds and Smith (1994) in- terannual anomalies of SST, and the Reverdin et al. (1994) surface currents climatology. The model is forced by a combination of ERS and TAO derived wind stresses (Menkes et al. 1998) and a mean seasonal cycle of surface heat and water fluxes derived from the ECMWF reanalysis.

The comparison against T/P altimetry (on the basis of 10-day averages) reveals good agreement between modeled and observed variability. Indeed, the model displays an average 0.8 correlation and $4.7 \mathrm{~cm}$ rms difference with $\mathrm{T} / \mathrm{P}$ data in the $10^{\circ} \mathrm{N}-10^{\circ} \mathrm{S}$ band.

Compared to TAO in situ temperature, the ERS + TAO run shows skill in capturing the main features of the tropical Pacific mean state. It nevertheless displays a lack of stratification in the lower thermocline, especially in the eastern part of the basin. Despite this bias, the phase of simulated variability is in good agreement with TAO 5-day temperatures, with correlation often above 0.8 in the upper $200 \mathrm{~m}$. The rms difference between model and observations is often between 1 and $2 \mathrm{~K}$ near the center of the thermocline, suggesting an underestimation of temperature variability in the thermocline region. This lack of variability can be linked to the diffuse model mean state.

The model does not use any relaxation to observed interannual anomalies of SST in its formulation. It can thus be validated against Reynolds and Smith (1994) SST interannual anomalies. The model reproduces qualitatively the main features of interannual variability, but underestimates its amplitude, as could be expected with a quite strong $\left(-40 \mathrm{~W} \mathrm{~m}^{-2} \mathrm{~K}^{-1}\right)$ relaxation to the seasonal SST climatology.

The model currents along the equator are close to those measured by TAO moorings. The agreement is good in the surface layer. Deeper, the model underestimates slightly the equatorial undercurrent strength (by 0.1 to $0.2 \mathrm{~m} \mathrm{~s}^{-1}$ ). The variability is good, with correlation between model and observed 5-day currents above 0.7 almost everywhere.

Finally, the model shows a qualitative agreement with Reverdin et al. (1994) surface current climatology. However, the modeled SEC is stronger than observed by about $0.1 \mathrm{~m} \mathrm{~s}^{-1}$ and penetrates too far west. The model also underestimates the North Equatorial Counter Current by about $0.1 \mathrm{~m} \mathrm{~s}^{-1}$.

The overall good agreement between the model and observations gives confidence in the study of the processes responsible for the SST variability in our experiment. First, the seasonal cycle during the 1993-96 period is investigated. As in previous observational studies (Bryden and Brady 1989; Wang and McPhaden 1999), the atmospheric forcing, and the cooling by the oceanic subsurface are found to be the main contributors to the seasonal cycle of SST in the eastern Pacific. Nonetheless, the effect of eddies is also very important. When tropical instability waves are active, they contribute greatly to transport horizontally heat to the equatorial band. The effect of zonal advection by low frequency 


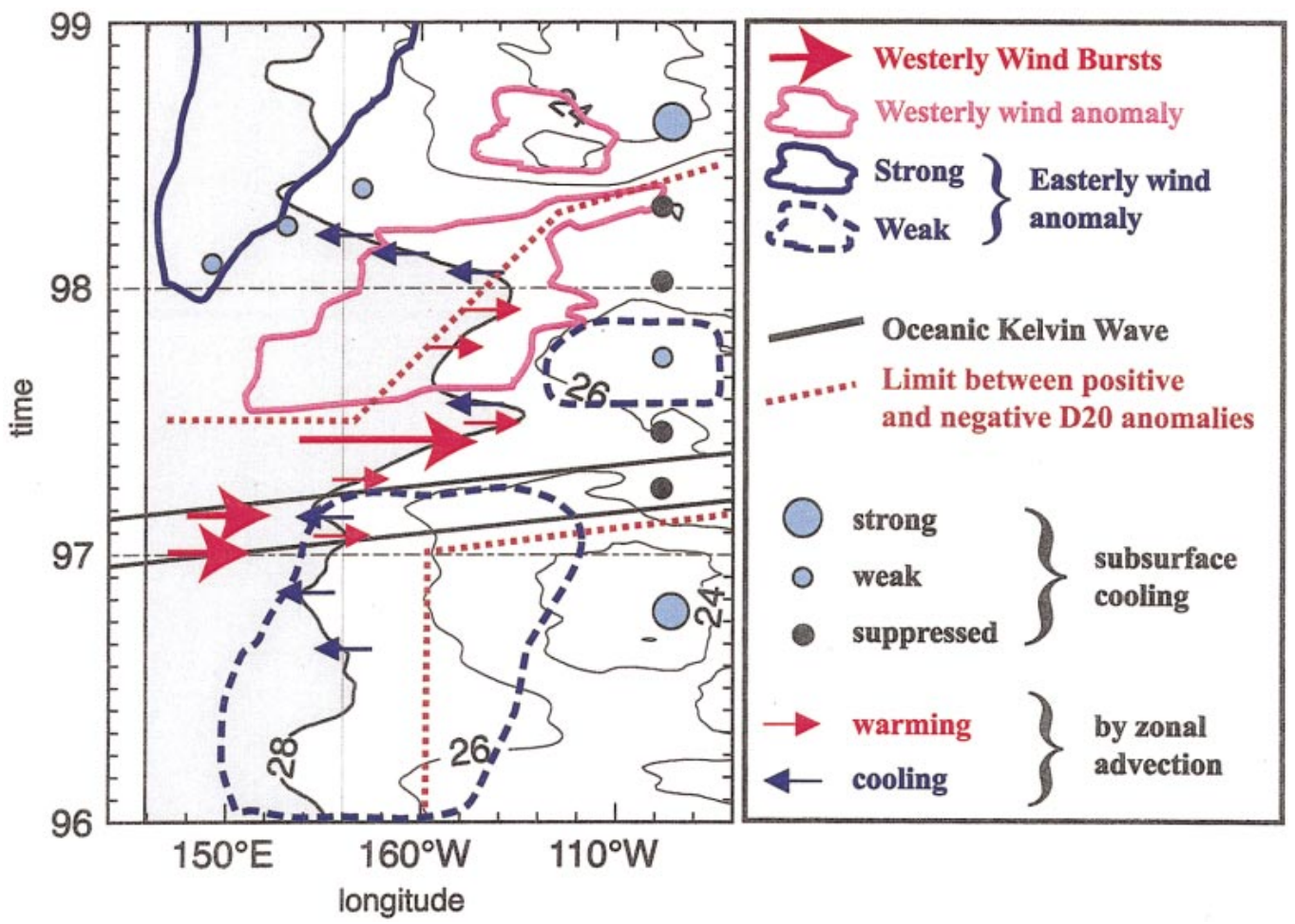

FIG. 14. Schematic representation of the main processes involved in the SST balance during the 1997-98 E1 Niño/La Niña.

currents is negligible. The meridional advection by low frequency currents contributes as a nearly constant cooling, especially active between the equator and $3^{\circ} \mathrm{N}$. In the western and central Pacific, the forcing is still the driving cause of the seasonal cycle, with the zonal advection by low frequency currents contributing to the cooling in the early year by advecting some water from the cold tongue.

Processes at work in the SST balance during the 1997-98 El Niño are then investigated. The suppression of the exchanges with the subsurface (upwelling, vertical mixing, entrainment) was found to be the main process responsible for the heating in the eastern Pacific. As the temperature rises, its effect is to diminish the atmospheric fluxes into the ocean, and (because of the diminished meridional gradient) to reduce heat export by meridional advection and its import by eddies. In the central and western Pacific, zonal advection by low frequency currents is the main process. Wind anomalies (either due to WWBs or large-scale wind response to anomalous SST) drive eastward currents that move the warm pool eastward. This is consistent with the results of (Picaut et al. 2001; Lagerloef et al. 1999; Boulanger and Menkes 2000).

The overall picture that can be drawn of the whole event is the following (see the Fig. 14 schematic representation). At the end of 1996, strong easterlies are the cause of a slightly enhanced cold tongue. Two very strong WWBs (in December 1996 and March 1997) occur in the western Pacific. The effect of the first one is diminished by increased easterlies afterward, but the second one plays a critical role in the El Niño event. Kelvin waves travel quickly to the east, and contribute strongly to lower the thermocline and diminish the cooling by subsurface processes. This results in a weakening of the equatorial tongue, and of its associated surfacelayer processes (heating by the atmosphere and by tropical instability waves, cooling by meridional advection). At the same time, due to eastward current anomalies (also driven by a third WWB in June 1997), the warm pool moves eastward until it reaches $140^{\circ} \mathrm{W}$. However, at this stage, there is still no clear sign of large-scale wind anomalies. The still strong easterlies thus reverse for a while the warming tendency: in the eastern Pacific by reactivating slightly the subsurface effects and in the central Pacific by pushing back the warm pool toward the west. However, around June, large-scale anomalies of the wind begin to develop over the western and central Pacific. Their effect is nearly instantly felt in the eastern Pacific, where the SST starts again to rise under the effect of thermocline deepening. In the central $\mathrm{Pa}-$ cific, there is a slower eastward displacement of the warm pool by zonal currents, as well as a slow eastward propagation of heat content. These features might be related to the slow coupled modes described by several studies (Neelin 1991; Wang et Weisberg 1994; Pontaud and Thual 1998). A consistent historical feature of past El Niños is the development of easterly anomalies in 
TABLE 1. Estimates of total zonal and meridional advection, forcing, and subsurface tendency contributions to the SST budget for this study and for Wang and McPhaden (1999). The estimates are given at four TAO moorings locations. The $90 \%$ confidence limit is given for WM. The mean value for 1993-96 is given for this study.

\begin{tabular}{|c|c|c|c|c|c|c|c|c|}
\hline & \multicolumn{2}{|c|}{$0^{\circ}, 165^{\circ} \mathrm{E}$} & \multicolumn{2}{|c|}{$0^{\circ}, 170^{\circ} \mathrm{W}$} & \multicolumn{2}{|c|}{$0^{\circ}, 140^{\circ} \mathrm{W}$} & \multicolumn{2}{|c|}{$0^{\circ}, 110^{\circ} \mathrm{W}$} \\
\hline & WM & $\begin{array}{l}\text { This } \\
\text { study }\end{array}$ & WM & $\begin{array}{l}\text { This } \\
\text { study }\end{array}$ & WM & $\begin{array}{l}\text { This } \\
\text { study }\end{array}$ & WM & $\begin{array}{l}\text { This } \\
\text { study }\end{array}$ \\
\hline Zonal advection & $-0.18 \pm 0.07$ & -0.31 & $-0.13 \pm 0.12$ & -0.40 & $-0.01 \pm 0.17$ & -0.08 & $-0.17 \pm 0.22$ & +0.50 \\
\hline Meridional advection & $+0.03 \pm 0.01$ & +0.13 & $+0.14 \pm 0.02$ & +0.28 & $+0.90 \pm 0.17$ & +0.71 & $+1.50 \pm 0.21$ & +1.51 \\
\hline Forcing & $+0.26 \pm 0.17$ & +0.40 & $+0.32 \pm 0.15$ & +0.89 & $+0.75 \pm 0.28$ & +1.31 & $+1.91 \pm 0.56$ & +2.83 \\
\hline Subsurface & $-0.11 \pm 0.12$ & -0.25 & $-0.32 \pm 0.12$ & -0.78 & $-1.63 \pm 0.26$ & -1.98 & $-3.22 \pm 0.78$ & -4.87 \\
\hline
\end{tabular}

the western Pacific during the peak and decay phases of the event (Rasmusson and Carpenter 1982). They also appeared in early 1998 (McPhaden 1999; Wang and Weisberg 2000). Under their effect, strong westward currents develop in the eastern and central Pacific, favoring cooling by upwelling and pushing back the warm pool in the west. Meanwhile, the thermocline rise slowly propagates eastward. This is the result of both direct wind forcing and western boundary reflection (Boulanger and Menkes 2000; McPhaden and Yu 1999). It is only when the thermocline rise reaches the eastern $\mathrm{Pa}-$ cific and suddenly reactivates cooling by the subsurface processes that the cold tongue reappears. Along with the cold tongue, heating by atmospheric fluxes, export of cold water by equatorial divergence, and heat transport by tropical instability waves resume.

\section{b. Discussion}

Despite an encouraging agreement with observations, there are some limitations to this model study. First of all, the representation of the fluxes as a climatology plus a feedback term [section $2 \mathrm{a}(2)$ ] is very crude. Furthermore, it implies that one must be careful when examining the seasonal cycle in the model. Indeed, the relaxation term might be working to compensate processes that are not well represented in the ocean model. For example, the underestimation of the vertical temperature gradients in the model [section $3 c(1)$ ] most certainly leads to an underestimate of the subsurface tendencies [which are directly linked to vertical gradients, as seen in Eq. (2)]. We saw, as well, that the SEC and its associated divergence were overestimated and penetrated too far west in the ERS + TAO experiment, presumably because of too strong wind stresses.

These systematic biases might lead to some inacurracies in the mean balance depicted by the model. It is thus useful to compare our estimates of the climatological tendencies to those of Wang and McPhaden (1999, hereafter WM). Table 1 shows a comparison for total zonal and meridional advection (we did not include the contribution from eddies in this comparison since WM do not separate it from advection by low frequency currents), forcing, and subsurface tendencies at four equatorial TAO moorings. The only significant difference appears for zonal advection at $110^{\circ} \mathrm{W}$, where $\mathrm{WM}$ is rather negative $\left(-0.170 \pm 2.2 \mathrm{~K} \mathrm{month}^{-1}\right)$, whereas we find a clearly positive value $\left(0.5 \mathrm{~K} \mathrm{month}^{-1}\right)$. We think that this discrepancy is mainly due to the effect of tropical instability waves in the zonal advection. It is clear from Fig. 8 that the coexistence of significant westward current and temperature gradient results in positive strong values of zonal advection in the southeastward flowing part of the TIW. Wang and McPhaden computed their budget using the Reynolds and Smith (1994) SST gradient. This product is obtained through an optimal interpolation (OI) analysis, which strongly smooths the SST structures associated to the TIWs. We thus think that WM underestimate the eddy contribution in their estimate of zonal advection, thus allowing zonal advection by the SEC (weaker, and of opposite sign) to dominate the budget. Except for this point of disagreement, the general pattern of the east-west gradient and the qualitative mean balance are well reproduced by the model for all tendencies. However, the model seems to overestimate cooling by subsurface processes and meridional advection in the east, and cooling by zonal advection in the central and western Pacific. This is consistent with too strong wind stress, upwelling, and SEC. This extra cooling is compensated by the relaxation of SST toward climatology (the forcing term in Table 1 warms the ocean more than in WM, whereas the agreement with WM is good when the relaxation term contribution is subtracted from the forcing). Wang and McPhaden do not explicitly compute the effect of eddies but some other studies do. The estimates of the eddy tendency from the model are in good agreement with those from observations. Bryden and Brady (1989) estimate an average heating by eddies of $1.6 \mathrm{~K}^{\text {month }}{ }^{-1}$ over the top $100 \mathrm{~m}$ between $110^{\circ}$ and $150^{\circ} \mathrm{W}$, along the equator. Our estimate is $1.1 \mathrm{~K} \mathrm{month}^{-1}$ over the mixed layer of the same region. Swenson and Hansen's (1999) estimate is $0.7 \mathrm{~K} \mathrm{month}^{-1}$ over the mixed layer of the $4^{\circ} \mathrm{S}-4^{\circ} \mathrm{N}, 100^{\circ}-130^{\circ} \mathrm{W}$ box, while ours is $0.9 \mathrm{~K}$ month ${ }^{-1}$ for the same domain. This gives confidence in our results, suggesting a significant role of instability waves to warm the equatorial band. This also justifies a posteriori the crude separation technique that was used to split advection terms into eddies and effect of low frequency currents.

The qualitative agreement between the simulated and observed interannual variability (recalling that no ob- 
served interannual SST product enters the model formulation) suggests that the experiment has captured the essence of real oceanic processes. However, while it is successful in reproducing some details of the evolution (like the June-August 1998 SST drop, as seen in Fig. 11), the model underestimates the SST anomaly during the 1997-98 El Niño. This is partly linked to the heat flux formulation: the $-40 \mathrm{~W} \mathrm{~m}^{-2} \mathrm{~K}^{-1}$ relaxation coefficient is certainly too strong (e.g., Gordon and Corry 1991), and the surface flux certainly behaves nonlinearly for large values of the SST anomaly (Seager 1989).

\section{c. Conclusions}

Several conclusions can be drawn from this study. First, we think that the quality of the simulations is due in large part to the quality of the wind stress forcing product. However, we can still identify some biases (e.g., the too strong SEC) that can be related to the forcing. It is thus very important to pursue efforts to produce high quality wind products. In particular, combining scatterometer information with in situ data, like here with ERS and TAO data, is certainly very promising. However, some of the biases identified in this study (like the diffuse model thermocline) are certainly related to the model formulation, and not to the forcing. Using isopycnal diffusion (Lengaigne et al. 2000, unpublished manuscript) helps, but does not solve all the problems. Increased vertical resolution or finer tuning of the vertical mixing scheme might need to be investigated.

Second, a paradox seems to come out of this study. The TIW contribution to the surface-layer heat budget is important in the eastern Pacific. This is not only true for the mean balance, but also at interannual timescales. During an El Niño, the quantity of heat advected horizontally toward the equator by eddies strongly diminishes. The interannual anomaly of the eddy contribution thus appears as a significant negative feedback to the growth of the El Niño events (Fig. 12c). This does not seem to be a model artefact since our estimate of the effect of the TIWs is in good agreement with observational studies. So, if the effect of TIWs is such an important contribution to the heat budget during an El Niño, how can simple models, that do not reproduce these processes, be so successful in forecasting ENSO events (e.g., Boulanger and Menkes 2000)? The answer might be that TIWs not only modify strongly the horizontal advection tendencies, but also the vertical ones. TIWs are indeed associated to strong vertical velocities and important mixed layer depth fluctuations. Our estimate of the mean subsurface tendency (Fig. 7) is asymmetric, partly because of TIWs. So the effect of TIWs is to bring heat horizontally, but also to remove heat by vertical processes. So the overall effect of instability waves on the tropical strip might be much weaker than previously estimated. To our knowledge, this compen- sation effect has not been studied yet. We will investigate it in a future study.

Several studies have emphasized the interaction between ENSO and the seasonal cycle (e.g., Tziperman et al. 1994; Jin et al. 1994; Galanti and Tziperman 2000). This suggests that it is useful to include the seasonal cycle in the description of an El Niño event. We would indeed like to underscore the fact that linearizing about the seasonal cycle, though mathematically correct, can be very misleading. For example, after June 1997, the thermocline was so depressed in the eastern Pacific, that the total subsurface tendency was close to zero and remained so until March 1998. The increase of the interannual anomaly of the subsurface tendency during 1997 thus only originates from the subtracted seasonal cycle. The same effect shows up with TIWs: the anomaly due to eddies becomes ever more negative from April to October 1997. In fact, the warming effect of eddies has been suppressed from the very start of the period, and the total eddy tendency stays constant and weak all along. In this specific case, it is easier to describe what happens in terms of total signal: the cold tongue disappears because of subsurface tendencies, which leads to the disruption of warming by TIW.

This study is a forced ocean study. This limits the interpretation that can be made in terms of coupled mechanisms. Together with other studies, it still allows us to discuss the processes that were essential in the triggering and decay of the 1997-98 El Niño. The delayed oscillator mechanism underlines the importance of Rossby wave reflection at the western boundary in the onset of El Niño (e.g., Battisti 1988). The picture that comes out from this study, together with others (McPhaden 1999), rather suggests a clear role of WWBs in triggering the 1997-98 El Niño. The signal of reflected Rossby wave at the western boundary was indeed dwarfed by the effect of WWBs (Yu and McPhaden 1999). The clearest effect of the December 1996 and March 1997 WWBs is in the east, quickly reached by downwelling Kelvin waves that suppresses subsurface cooling in early 1997. In contrast, the formation of a temperature anomaly in the central Pacific is slow. It indeed appears through eastward advection of the warm pool, typically at $0.5 \mathrm{~m} \mathrm{~s}^{-1}$, in contrast to the $2.5 \mathrm{~m} \mathrm{~s}^{-1}$ of Kelvin wave propagation (this study; but also Picaut et al. 2001; Lagerloef et al. 1999). The two aforementioned WWBs, and a third in June 1997, were essential in setting up the eastward jet that moved the warm pool edge to the east. The central Pacific is a key region for an atmospheric low frequency response to set up. So, while the warming due to the Kelvin waves (via subsurface processes) stays stationary in the east (the total SST even cools down, because of resuming easterlies), key air-sea interaction processes develop in the central Pacific. Indeed, from June onward, large-scale persistent anomalies of the wind stress appear and propagate to the east, along with the SST anomaly, heat content anomaly, and zonal current anomalies. The main oceanic 
process for the eastward extension of the SST anomaly is zonal advection. This is in qualitative agreement with the coupled mode description of Neelin (1991) and Pontaud and Thual (1998), with zonal advection positive retroaction as the main process. Similarly, the end of the 1997-98 event does not seem to be explained only in terms of wave reflections, as suggested by the delayed oscillator conceptual model. We indeed find that cooling of the SST is both due to the resuming of a westward current and upwelling in the west, and to restored subsurface cooling, because of the rising thermocline in the east. Yu and McPhaden (1999) found that these signals (westward currents, thermocline rise propagating eastward) could not be explained in terms of reflection at the western boundary only. The easterly wind anomalies that developed in November 1997 (Wang and Weisberg 2000) explain a large part of this signal. These winds in the western Pacific at the end of the year are a consistent historical feature of El Niño (Rasmusson and Carpenter 1982). They should be included in the coupled mode description, since they favor the termination of the El Niño.

Acknowledgments. Jérôme Vialard did part of this work while at ECMWF. He would like to thank the ECMWF seasonal forecasting group for the stimulating environment they provided. Marie-Hélène Radenac provided a lot of input on the validation of the experiments. Gaël Alory did some of the early validation. Sebastien Masson has developed a wonderful plotting environment based on IDL ${ }^{\mathrm{TM}}$, that made all the diagnostics so much easier. Thank you to Gilles Reverdin for his careful reading of the manuscript. Arthur J. Miller and an anonymous referee provided very useful comments. All this study would not have been possible without the work of Maurice Imbard and Claire Levy in developing and maintaining the ocean model. Christophe Menkes is funded by IRD. Jean-Philippe Boulanger, Pascale Delecluse, and Gurvan Madec are funded by CNRS. All the computations were performed on IDRIS supercomputers.

\section{REFERENCES}

Arakawa, A., 1972: Design of the UCLA general circulation model. Numerical simulation of weather and climate. Tech. Rep. 7, Dept. of Meteorology, University of California, $116 \mathrm{pp}$.

Barnett, T. P., M. Latif, M. Kirk, and E. Roeckner, 1991: On ENSO physics. J. Climate, 4, 487-514.

Battisti, D. S., 1988: Dynamics and thermodynamics of a warming event in a coupled tropical atmosphere-ocean model. J. Atmos. Sci., 45, 2889-2919.

Baturin, N. G., and P. P. Niiler, 1997: Effects of instability waves in the mixed layer of the equatorial Pacific. J. Geophys. Res., 102, 27 771-27 793.

Bentamy, A., Y. Quilfen, F. Gohin, N. Grima, M. Lenaour, and J. Servain, 1996: Determination and validation of average wind fields from ERS-1 scatterometer measurements. Global Atmos. Ocean Syst., 4, 1-29.

Blanke, B., and P. Delecluse: 1993, Variability of the tropical Atlantic
Ocean simulated by a general circulation model with two different mixed layer physics. J. Phys. Oceanogr., 23, 1363-1388. Boulanger, J.-P., 2000: The Trident Pacific model. Part 1: The oceanic dynamical model during the TOPEX/Poseidon period. Climate Dyn., in press.

, and C. Menkes, 1999: Long equatorial wave reflection in the Pacific Ocean from the TOPEX/Poseidon data running the 199298 period. Climate Dyn., 15, 15 205-15 225.

- and — 2000: The Trident Pacific model. Part 2: The thermodynamical model and the role of long equatorial wave reflections during the TOPEX/Poseidon period. Climate Dyn., in press.

Bryden, H. L., and E. C. Brady, 1985: Diagnostic model of the threedimensional circulation in the upper equatorial Pacific Ocean. $J$. Phys. Oceanogr., 15, 1255-1273.

— effects on the circulation of the equatorial Pacific Ocean. J. Mar. Res., 47, 55-79.

DeWitt, D. G., and E. K. Schneider, 1999: The processes determining the annual cycle of equatorial sea surface temperature: A coupled general circulation model perspective. Mon. Wea. Rev., 127, 381-395.

Enfield, D. B., 1986: Zonal and seasonal variations in the near surface heat balance of the equatorial ocean. J. Phys. Oceanogr., 16, $1038-1054$.

Flament, P., S. C. Kennan, R. Knox, P. P. Niiler, and R. Bernstein, 1996: The three-dimensional structure of an upper vortex in the tropical Pacific. Nature, 382, 610-613.

Frankignoul, C., F. Bonjean, and G. Reverdin, 1996: Interannual variability of surface currents in the tropical Pacific during 198793. J. Geophys. Res., 101, 3629-3647.

Galanti, E., and E. Tziperman, 2000: On ENSO's phase locking to the seasonal cycle in the fast SST, fast wave and mixed mode regimes. J. Atmos. Phys. 57, 2936-2950.

Gibson, R., P. Kallberg, S. Uppala, A. Hernandez, A. Nomura, and E. Serrano, 1997: ERA descripton. ECMWF Re-Analysis Project Rep. Ser., No. 1, ECMWF, Reading, United Kingdom, 71 pp.

Glantz, M. H., 1996: Currents of Change: E1 Niño's Impact on Climate and Society. Cambridge University Press, $194 \mathrm{pp}$.

Gordon, C., and R. A. Corry, 1991: A model simulation of the seasonal cycle in the tropical Pacific Ocean using climatological and modelled surface forcing. J. Geophys. Res., 96, 847-864.

Grima, N., A. Bentamy, K. Katsaros, Y. Quilfen, P. Delecluse, and C. Levy, 1999: Sensitivity of an oceanic general circulation model forced by satellite wind stress fields. J. Geophys. Res., 104, 7967-7989.

Hansen, D., and C. Paul, 1984: Genesis and effect of long waves in the equatorial Pacific. J. Geophys. Res., 89, 10 341-10 440.

Harrison, D. E., B. S. Giese, and E. S. Sarachik, 1990: Mechanisms of SST change in the equatorial waveguide during the 1982-83 ENSO. J. Climate, 3, 173-188.

Hayes, S. P., P. Chang, and M. J. McPhaden, 1991: Variability of the sea surface temperature in the eastern equatorial Pacific during 1986-88. J. Geophys. Res., 96, 10 553-10 566.

Huang, B., and E. K. Schneider, 1995: The response of an ocean general circulation model to surface wind stress produced by an atmospheric general circulation model. Mon. Wea. Rev., 123, 3059-3085.

Jackett, D. R., and T. J. McDougall, 1995: Minimal adjustment of hydrographic data to achieve static stability. J. Atmos. Oceanic Technol., 12, 381-389.

Jin, F. F., D. Neelin, and M. Ghil, 1994: ENSO on devil's staircase. Science, 264, 70-72.

Kennan, S. C., and P. Flament, 2000: Observations of a tropical instability vortex. J. Phys. Oceanogr., 30, 2277-2301.

Lagerloef, G. S. E., G. Mitchum, R. Lukas, and P. Niiler, 1999: Tropical Pacific surface currents with altimeter, wind, and drifter data. J. Geophys. Res. 104, 23313-23326.

Lazar, A., G. Madec, and P. Delecluse, 1999: The deep interior downwelling, the Veronis effect, and mesoscale tracer transport pa- 
rameterizations in an OGCM. J. Phys. Oceanogr., 29, 29452961.

Legeckis, R., 1977: Long waves in the eastern equatorial Pacific Ocean: A view from a geostationary satellite. Science, 197, 1179-1181.

Levitus, S., 1982: Climatological Atlas of the World Ocean. NOAA Prof. Paper No. 13, U.S. Govt. Printing Office, 173 pp. and 17 microfiche.

Liu, W. T., K. B. Katsaros, and J. A. Businger, 1979: Bulk parameterization of air-sea exchanges of heat and water vapor including the molecular constraints at the interface. J. Atmos. Sci., 36, $1722-1735$.

Madec, G., P. Delecluse, M. Imbard, and C. Levy, 1999: OPA 8.1 Ocean General Circulation Model reference manual. Notes du pôle de modélisation, Vol. 11, Institut Pierre Simon Laplace (IPSL), $91 \mathrm{pp}$.

Maes, C., G. Madec, and P. Delecluse, 1997: Sensitivity of an equatorial pacific OGCM to the lateral diffusion. Mon. Wea. Rev., 125, 958-971.

McCarty, M. E., and M. J. McPhaden, 1993: Mean seasonal cycles and interannual variations at $0,165 \mathrm{E}$ during $1986-1992$. NOAA Tech. Memo. ERL PMEL-98, 64 pp.

McCreary, J. P., and Z. Yu, 1992: Equatorial dynamics in a 2.5-layer model. Progress in Oceanography, Vol. 29, Pergamon, 61-132.

McPhaden, M. J., 1999: Genesis and evolution of the 1997-98 El Niño. Science, 283, 950-954.

— seasonal variability in the eastern equatorial Pacific. J. Phys. Oceanogr., 18, 1713-1732.

—- and X. Yu, 1999: Equatorial waves and the 1997-98 El Niño. Geophys. Res. Lett., 26, 2961-2964.

—_ A. Busalacchi, and J. Picaut, 1988: Observations and windforced simulations of the mean seasonal cycle in the tropical Pacific sea surface topography. J. Geophys. Res., 93, 8131-8146.

_ , and Coauthors, 1998: The Tropical Ocean-Global Atmosphere observing system: A decade of progress. J. Geophys. Res., 103, 14 169-14 240.

Menkes, C., J.-P. Boulanger, A. J. Busalacchi, J. Vialard, P. Delecluse, M. J. McPhaden, E. Hackert, and N. Grima, 1998: Impact of TAO vs. ERS wind stresses onto simulations of the tropical Pacific Ocean during the 1993-1998 period by the OPA OGCM. Euroclivar Workshop Rep. 13, 46-48.

Miller, A. J., J. M. Oberhuber, N. E. Graham, and T. P. Barnett, 1992 Tropical Pacific Ocean response to observed winds in a layered general circulation model. J. Geophys. Res., 97 (C5), 7317-7340.

_, T. P. Barnett, and N. E. Graham, 1993: A comparison of some tropical ocean models: Hindcast skill and El Niño evolution. $J$. Phys. Oceanogr., 23, 1567-1591.

Neelin, J. D., 1991: The slow SST mode and the fast wave limit: Analytic theory for tropical interannual oscillations and experiments in an hybrid coupled model. J. Atmos. Sci., 48, 584-605

Niiler, P. P., and E. B. Kraus, 1977: One-dimensional models of the upper ocean. Modelling and Prediction of the Upper Layers of the Ocean, E. B. Kraus, Ed., Pergamon, 143-172.

Oberhüber, J. M., 1988: An atlas based on the COADS data set: The budgets of heat, buoyancy and turbulent kinetic energy at the surface of the global ocean. Report 15, Max-Planck-Institut für Meteorologie, $20 \mathrm{pp}$.

Philander, S. G. H., 1976: Instabilities of zonal equatorial currents, Part 1. J. Geophys. Res., 81, 3725-3735.

, and A. D. Seigel, 1985: Simulation of El Niño of 1982-1983.
Coupled Ocean-Atmosphere Models, J. C. J. Nihoul, Ed., Elsevier, 517-541.

Picaut, J., M. Ioualalen, T. Delcroix, M. J. McPhaden, and C. Menkes, 1996: Mechanism of the zonal displacements of the Pacific warm pool: Implications for ENSO. Science, 274, 1486-1489.

—_. F. Masia, and Y. du Penhoat, 1997: An advective-reflective conceptual model for the oscillatory nature of the ENSO. Science, 277, 663-666.

-, M. Ioualalen, T. Delcroix, F. Masia, R. Murtugudde, and J. Vialard, 2001: Displacements of an oceanic zone of convergence on the eastern edge of the Pacific warm pool: Consequences for ENSO and biogeochemical phenomena. J. Geophys. Res. 106, 2363-2386.

Pontaud, M., and O. Thual, 1998: Coupled processes for equatorial Pacific interannual variability. Quart. J. Roy. Meteor. Soc., 124, $527-555$.

Proehl, J. A., 1996: Linear stability of equatorial zonal flows. J. Phys. Oceanogr., 26, 601-621.

Rasmunsson, E. M., and T. H. Carpenter, 1982: Variations in tropical sea surface temperature and surface wind fields associated with the Southern Oscillation/El Niño. Mon. Wea. Rev., 110, 354384.

Reverdin, G., C. Frankignoul, E. Kestenare, and M. J. McPhaden, 1994: Seasonal variability in the surface currents of the equatorial Pacific. J. Geophys. Res., 99, 20 323-20 344.

Reynolds, R. W., and T. M. Smith, 1994: Improved global sea surface temperature analyses. J. Climate, 7, 929-948.

Seager, R., 1989: Modeling tropical Pacific sea surface temperature: 1970-87. J. Phys. Oceanogr., 19, 419-434.

Smith, S. D., 1988: Coefficients for sea surface wind stress, heat flux and wind profiles as a function of wind speed and temperature. J. Geophys. Res., 93, 15 467-15 472.

Stevenson, J. W., and P. P. Niiler, 1983: Upper ocean heat budget during the Hawaii-to-Tahiti shuttle experiment. J. Phys. Oceanogr., 13, 1894-1907.

Swenson, M. S., and D. V. Hansen, 1999: Tropical Pacific Ocean mixed layer heat budget: The pacific cold tongue. J. Phys. Oceanogr., 29, 83-91.

Tziperman, E. L., M. Cane, and H. Jarosh, 1994: El Niño chaos: Overlapping of resonances between the seasonal cycle and the Pacific Ocean-atmosphere oscillator. Science, 264, 72-74.

Vialard, J., 1997: Influence de la salinité sur les interactions couplées océan-atmosphère dans le Pacifique Ouest. Ph.D. thesis, l'Université Pierre et Marie Curie, Paris, France, 218 pp.

_ , and P. Delecluse, 1998a: An OGCM study for the TOGA decade. Part I: Role of salinity in the physics of the western Pacific fresh pool. J. Phys. Oceanogr., 28, 1071-1088.

— II: Barrier layer formation and variability. J. Phys. Oceanogr., 28, 1089-1106.

Wang, C., and R. H. Weisberg, 1994: On the "slow mode" mechanism in ENSO-related coupled ocean-atmosphere models. J. Climate, 7, 1657-1667.

— , and — 2000: The 1997-98 evolution relative to previous El Niño events. J. Climate, 13, 488-501.

Wang, W., and M. J. McPhaden, 1999: The surface layer heat balance in the equatorial Pacific Ocean. Part I: Mean seasonal cycle. $J$. Phys. Oceanogr., 29, 1812-1831.

Wyrtki, K., 1981: An estimate of equatorial upwelling in the Pacific. J. Phys. Oceanogr., 11, 1205-1214.

Yu, X., and M. J. McPhaden, 1999: Seasonal variability in the equatorial Pacific. J. Phys. Oceanogr., 29, 925-947. 